NASA/TM-2007-214673

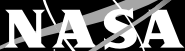

Composite Nanomechanics: A Mechanistic Properties Prediction

Christos C. Chamis, Louis M. Handler, and Jane Manderscheid Glenn Research Center, Cleveland, Ohio 


\section{NASA STI Program . . . in Profile}

Since its founding, NASA has been dedicated to the advancement of aeronautics and space science. The NASA Scientific and Technical Information (STI) program plays a key part in helping NASA maintain this important role.

The NASA STI Program operates under the auspices of the Agency Chief Information Officer. It collects, organizes, provides for archiving, and disseminates NASA's STI. The NASA STI program provides access to the NASA Aeronautics and Space Database and its public interface, the NASA Technical Reports Server, thus providing one of the largest collections of aeronautical and space science STI in the world. Results are published in both non-NASA channels and by NASA in the NASA STI Report Series, which includes the following report types:

- TECHNICAL PUBLICATION. Reports of completed research or a major significant phase of research that present the results of NASA programs and include extensive data or theoretical analysis. Includes compilations of significant scientific and technical data and information deemed to be of continuing reference value. NASA counterpart of peer-reviewed formal professional papers but has less stringent limitations on manuscript length and extent of graphic presentations.

- TECHNICAL MEMORANDUM. Scientific and technical findings that are preliminary or of specialized interest, e.g., quick release reports, working papers, and bibliographies that contain minimal annotation. Does not contain extensive analysis.

- CONTRACTOR REPORT. Scientific and technical findings by NASA-sponsored contractors and grantees.
- CONFERENCE PUBLICATION. Collected papers from scientific and technical conferences, symposia, seminars, or other meetings sponsored or cosponsored by NASA.

- SPECIAL PUBLICATION. Scientific, technical, or historical information from NASA programs, projects, and missions, often concerned with subjects having substantial public interest.

- TECHNICAL TRANSLATION. Englishlanguage translations of foreign scientific and technical material pertinent to NASA's mission.

Specialized services also include creating custom thesauri, building customized databases, organizing and publishing research results.

For more information about the NASA STI program, see the following:

- Access the NASA STI program home page at http://www.sti.nasa.gov

- E-mail your question via the Internet to help@sti.nasa.gov

- Fax your question to the NASA STI Help Desk at 301-621-0134

- Telephone the NASA STI Help Desk at 301-621-0390

- Write to: NASA Center for AeroSpace Information (CASI) 7115 Standard Drive Hanover, MD 21076-1320 
NASA/TM-2007-214673

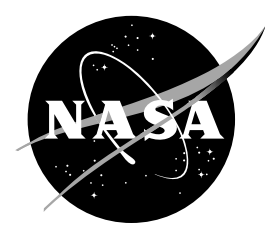

\section{Composite Nanomechanics: A Mechanistic Properties Prediction}

Christos C. Chamis, Louis M. Handler, and Jane Manderscheid Glenn Research Center, Cleveland, Ohio

National Aeronautics and

Space Administration

Glenn Research Center

Cleveland, Ohio 44135 
This work was sponsored by the Fundamental Aeronautics Program at the NASA Glenn Research Center.

Level of Review: This material has been technically reviewed by technical management.

Available from

NASA Center for Aerospace Information 7115 Standard Drive

Hanover, MD 21076-1320
National Technical Information Service 5285 Port Royal Road Springfield, VA 22161

Available electronically at http://gltrs.grc.nasa.gov 


\section{Contents}

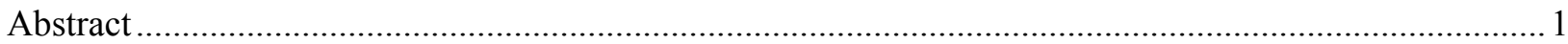

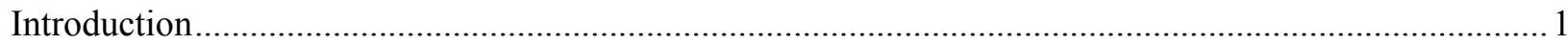

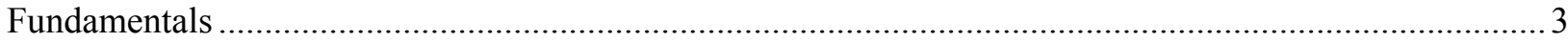

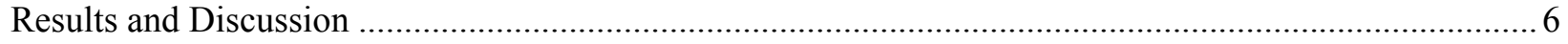

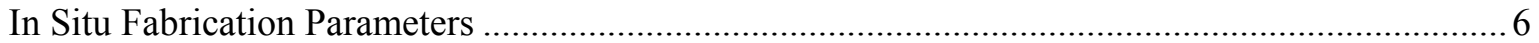

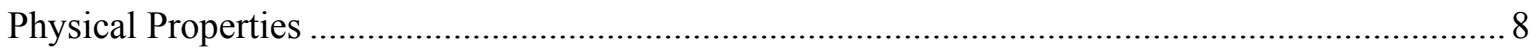

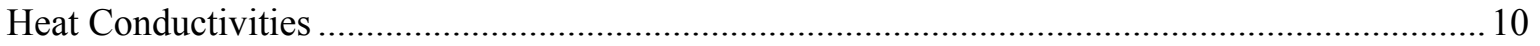

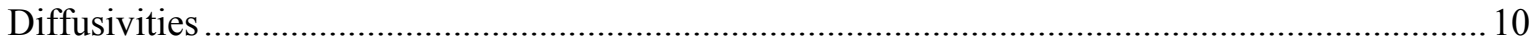

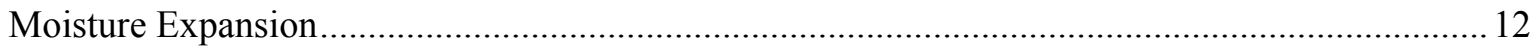

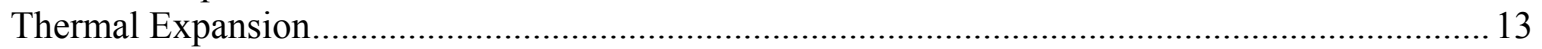

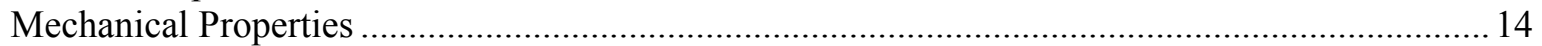

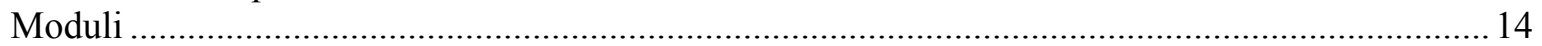

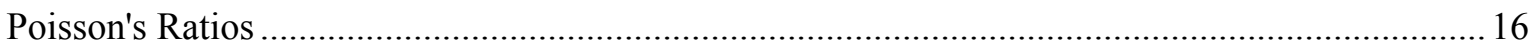

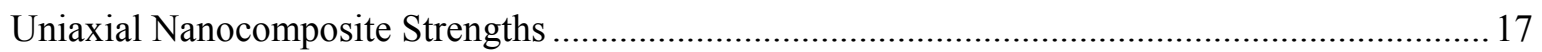

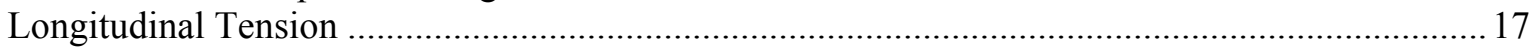

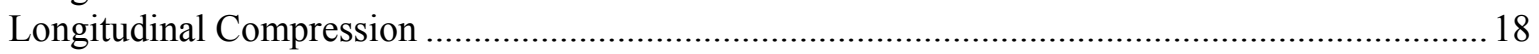

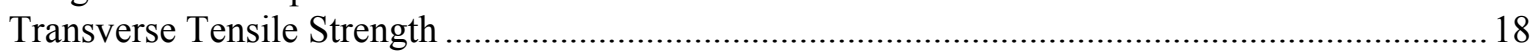

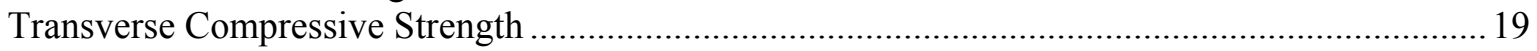

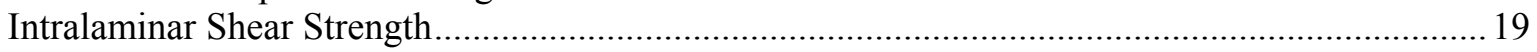

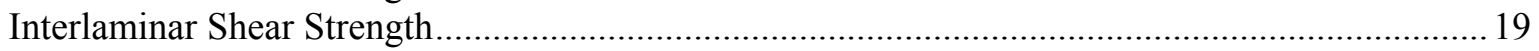

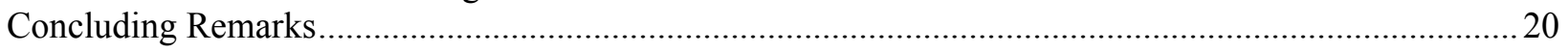

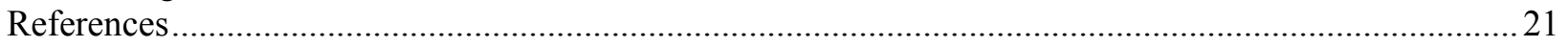





\title{
Composite Nanomechanics: A Mechanistic Properties Prediction
}

\author{
Christos C. Chamis, Louis M. Handler, and Jane M. Manderscheid \\ National Aeronautics and Space Administration \\ Glenn Research Center \\ Cleveland, Ohio 44135
}

\begin{abstract}
A unique mechanistic theory is described to predict the properties of nanocomposites. The theory is based on composite micromechanics with progressive substructuring down to a nanoscale slice of a nanofiber where all the governing equations are formulated. These equations have been programmed in a computer code. That computer code is used to predict 25 properties of a mononanofiber laminate. The results are presented graphically and discussed with respect to their practical significance. Most of the results show smooth distributions. Results for matrix-dependent properties show bimodal through-thethickness distribution with discontinuous changes from mode to mode.
\end{abstract}

\section{Introduction}

The research in the nanoscale technology has exploded over the recent past. An indication of this explosion is that the SAMPE (Society of Aerospace Material and Processing Engineers) Conference is devoting four sessions of about six papers each in the last 3 years. These papers cover practically all current research activities. The majority of the research is devoted to processing because of the difficulties involved in making a useful material (ref. 1). A few investigators have been fortunate to make some testing samples, which they subsequently tested to obtain limited data (ref. 2). A few other investigators researched the characterization of fatigue (ref. 3) and creep (ref. 4). A couple of papers explored the construction of nanocomposites for rocket ablative material (ref. 5) and for carbon nanotubes for adaptive structures (ref. 6). One paper ventured to describe a computer simulation of macroscopic properties of carbon nanotubes polymer composites (ref. 7). However, there are no results of what special macroscopic properties are included. Reference 7 shows one stress strain curve and citation of several references. One recent article (ref. 8) describes multiscale modeling and simulation of nanostructural materials from atomistic to micromechanics. This article does not include information on nanocomposites, but it mentions that mechanistic models will be needed in the end. It is becoming abundantly clear that no holistic approach has been used to investigate the mechanistic prediction of all nanocomposite uniaxial properties: fabrication parameters (3), physical (10), mechanical moduli (6), and uniaxial strengths (6), (ref. 9), which is the objective of the research reported herein.

Herein a unique mechanistic method is described, which is used to predict all 25 nanocomposite properties. The method is unique because it is based on composite mechanics that are reduced down to nanoscale by progressive substructuring. At the nanoscale the same assumptions are made that are consistent with those made in the composite mechanics. The method is illustrated by applying it to an assumed nanofiber aligned laminate of one nanofiber diameter $\left(2.756 \times 10^{-6} \mathrm{in}\right.$.). The properties are then predicted by all the composite micromechanics equations, which are formulated on a thin slice of the substructured nanofiber. The substructuring and the equations are programmed in an in-house computer code called ICAN/JAVA (ref. 10). A logic block diagram of ICAN/JAVA for application to nanocomposites is shown in figure 1. It is assumed that the nanofiber is a graphite fiber (Pyrograf II, Applied Sciences Incorporated) with modulus $1.0 \times 10^{9} \mathrm{psi}$ and a tensile strength of 0.8 million psi. The remaining properties are estimated to be those from a Thornel 300 fiber (table 1) and IntermediateModulus High-Strength Matrix (Epoxy), table 2. The fiber volume ratio is about 0.05 , and is about the same as that for the Pyrograf (private communication). 


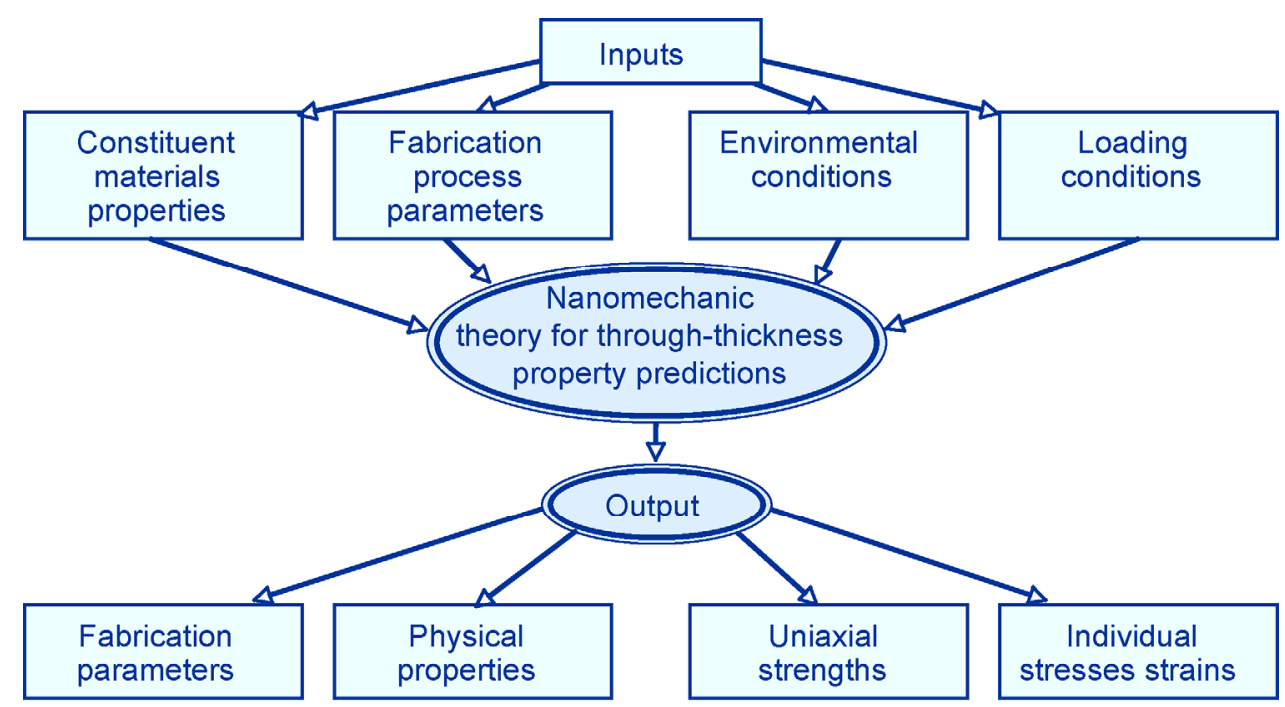

Figure 1.-Mechanistic approach to nanocomposites mechanics.

TABLE I.-T300 GRAPHITE NANOFIBER (PYROGRAF II) PROPERTIES

\begin{tabular}{|c|c|c|c|}
\hline Description & Symbol & Value & Units \\
\hline Number of fibers per end & $\mathrm{Nf}$ & 1.0 & number \\
\hline Filament equivalent diameter & df & $2.756 \times 10^{-6}$ & in. \\
\hline Weight density & Rhof & 0.064 & lb/in. $* * 3$ \\
\hline Normal moduli (11) & Ef11 & $1.0 \times 10^{9}$ & psi \\
\hline Normal moduli (22) & Ef22 & $7.0 \times 10^{7}$ & psi \\
\hline Poisson's ratio (12) & Nuf12 & 0.2 & Nondimensional \\
\hline Poisson's ratio (23) & Nuf23 & 0.25 & Nondimensional \\
\hline Shear moduli (12) & Gf12 & $5.0 \times 10^{7}$ & psi \\
\hline Shear moduli (23) & Gf23 & $3.5 \times 10^{7}$ & psi \\
\hline Thermal expansion coefficient (11) & A1fafl1 & $-5.5 \times 10^{-7}$ & in. $/$ in. $/{ }^{\circ} \mathrm{F}$ \\
\hline Thermal expansion coefficient (22) & Alfaf22 & $5.6 \times 10^{-6}$ & in. $/$ in. $/{ }^{\circ} \mathrm{F}$ \\
\hline Heat conductivity (11) & Kf11 & 444.0 & $\mathrm{Btu} / \mathrm{hr} / \mathrm{ft}^{2} /{ }^{\circ} \mathrm{F} /$ in. \\
\hline Heat conductivity (22) & $\mathrm{Kf} 22$ & 4.0 & $\mathrm{Btu} / \mathrm{hr} / \mathrm{ft}^{2} /{ }^{\circ} \mathrm{F} / \mathrm{in}$. \\
\hline Heat capacity & $\mathrm{Cf}$ & 0.22 & $\mathrm{Btu} / \mathrm{lb} /{ }^{\circ} \mathrm{F}$ \\
\hline Dielectric strength (11) & KeF11 & 0.0 & V/in. \\
\hline Dielectric strength (22) & Kef22 & 0.0 & V/in. \\
\hline Dielectric constant (11) & Gamma11 & 0.0 & in. $/ \mathrm{V}$ \\
\hline Dielectric constant (22) & Gamma22 & 0.0 & in. $/ \mathrm{V}$ \\
\hline Capacitance & Cef & 0.0 & V \\
\hline Resistivity & Ref & 0.0 & $\Omega$-in. \\
\hline Tensile strength & SfT & $8.0 \times 10^{5}$ & psi \\
\hline Compressive strength & $\mathrm{SiC}$ & $6.0 \times 10^{5}$ & psi \\
\hline Shear strength & SfS & $4.0 \times 10^{5}$ & psi \\
\hline Normal damping capacity (11) & psi11f & 0.38 & $\%$ Energy \\
\hline Normal damping capacity (22) & psi22f & 6.3 & $\%$ Energy \\
\hline Shear damping capacity (12) & psi12f & 3.34 & $\%$ Energy \\
\hline Shear damping capacity (23) & psi23f & 6.3 & \%Energy \\
\hline Melting temperature & TMf & 6000.0 & ${ }^{\circ} \mathrm{F}$ \\
\hline
\end{tabular}


TABLE II.-INTERMEDIATE MODULUS HIGH-STRENGTH MATRIX (EPOXY)

\begin{tabular}{|c|c|c|c|}
\hline Description & Symbol & Value & Units \\
\hline Weight density & Rhom & 0.044 & lb/in.**3 \\
\hline Normal modulus & Em & 500000.0 & psi \\
\hline Poisson's ratio & Num & 0.35 & Nondimensional \\
\hline Thermal expansion coefficient & Alfa $\mathrm{m}$ & $3.6 \times 10^{-5}$ & in. $/$ in. $/{ }^{\circ} \mathrm{F}$ \\
\hline Heat conductivity & $\mathrm{Km}$ & 0.008681 & $\mathrm{Btu} / \mathrm{hr} / \mathrm{ft}^{2} /{ }^{\circ} \mathrm{F} /$ in. \\
\hline Heat capacity & $\mathrm{Cm}$ & 0.25 & $\mathrm{Btu} / \mathrm{lb} /{ }^{\circ} \mathrm{F}$ \\
\hline Dielectric strength & Kem & 0.0 & V/in. \\
\hline Dielectric constant & Gammam & 0.0 & in. $/ \mathrm{V}$ \\
\hline Capacitance & Cem & 0.0 & V \\
\hline Resistivity & Rem & 0.0 & $\Omega$-in. \\
\hline Moisture expansion coefficient & Betam & 0.0033 & in./in. $/ \%$ moisture \\
\hline Diffusivity & $\mathrm{Dm}$ & $2.16 \times 10^{-7}$ & in. $* * 2 / \mathrm{hr}$ \\
\hline Saturation & $\mathrm{Mm}$ & 0.0 & $\%$ moisture \\
\hline Tensile strength & $\mathrm{SmT}$ & 15000.0 & psi \\
\hline Compressive strength & $\mathrm{SmC}$ & 35000.0 & psi \\
\hline Shear strength & $\mathrm{SmS}$ & 13000.0 & psi \\
\hline Allowable tensile strain & eps mT & 0.02 & in./in. \\
\hline Allowable compression strain & eps $\mathrm{mC}$ & 0.05 & in./in. \\
\hline Allowable shear strain & eps $\mathrm{mS}$ & 0.035 & in./in. \\
\hline Allowable torsional strain & eps mTOR & 0.035 & in./in. \\
\hline Normal damping capacity & psiNM & 6.6 & \%energy \\
\hline Shear damping capacity & psiSm & 6.9 & \%energy \\
\hline Void heat conductivity & $\mathrm{Kv}$ & 0.0012 & $\mathrm{Btu} / \mathrm{hr} / \mathrm{in} . /{ }^{\circ} \mathrm{F}$ \\
\hline Glass transition temperature & Tgdr & 420.0 & ${ }^{\circ} \mathrm{F}$ \\
\hline Melting temperature & TMm & 0.0 & ${ }^{\circ} \mathrm{F}$ \\
\hline
\end{tabular}

It is important that the reader keeps in mind that the emphasis herein is on the method used. The properties obtained are for illustrative purposes only and will depend on the specific input (tables 1 and 2). The simplified equations used (refs. 11 and 12) are summarized before each corresponding set of results presented.

\section{Fundamentals}

The fiber alignment with uniform dispersion is not met in nanocomposites. It is assumed herein that the fibers are aligned only for predicting "point" through-the-thickness properties. The fussiness can be simulated by estimating the angle of single fibers through the thickness. Therefore, it is assumed that an aligned unidirectional typical section of a nanocomposite is as illustrated schematically in figure 2 on the left. A nanoply is schematically shown in figure 2 on the right. It is interesting to note that the substructuring into slices the monofiber nanoply is not constrained by the maximum fiber volume ratio, even though the monofiber was assumed to be in a square array with a limiting fiber volume ratio of about 0.78 . A block diagram depicting a mechanistic approach to nanoscale mechanics is shown in figure 1, as was mentioned previously. This diagram shows the three major parts of nanoscale mechanics: (1) input, (2) mechanics theory for through-the-thickness predictions of properties, and (3) output. The input includes the constituent material properties, the fabrication parameters, environmental, and the loading conditions. The nanomechanics theory includes all the equations that are required to predict the output. The output includes the fabrication parameters as are present in the nanocomposite, the physical properties, the mechanical properties, and individual uniaxial strengths.

The properties prediction is expedited by the following geometric diagrams: (1) A typical section of the nanocomposite shown in figure 2(a) and a nanoply in figure 2(b). (2) An exploded view of nanoscale isolation of a typical part is shown in figure 3 with nanoscale dimensions. (3) A single nanofiber schematic with substructuring is shown in figure 4(a), and a typical subslice is shown in figure 4(b). A 


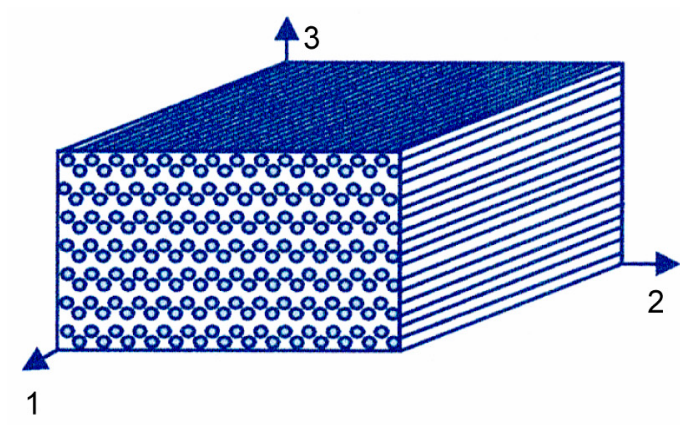

(a)

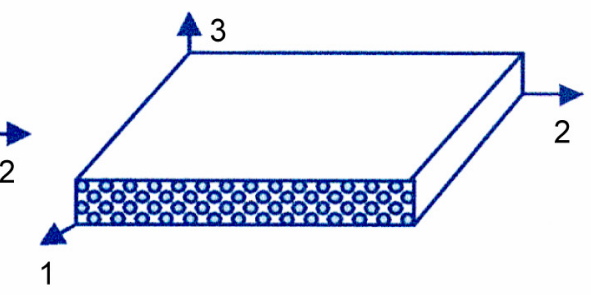

(b)

Figure 2.-Unidirectional nanocomposite typical section. (a) Nanocomposite. (b) Nanoply.

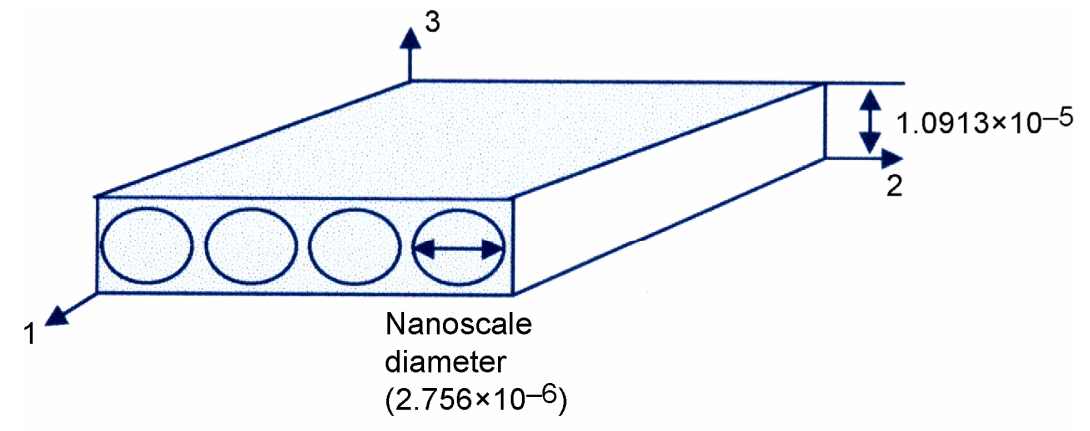

Figure 3.-Nanoscale isolation of a typical part (units are in inches).

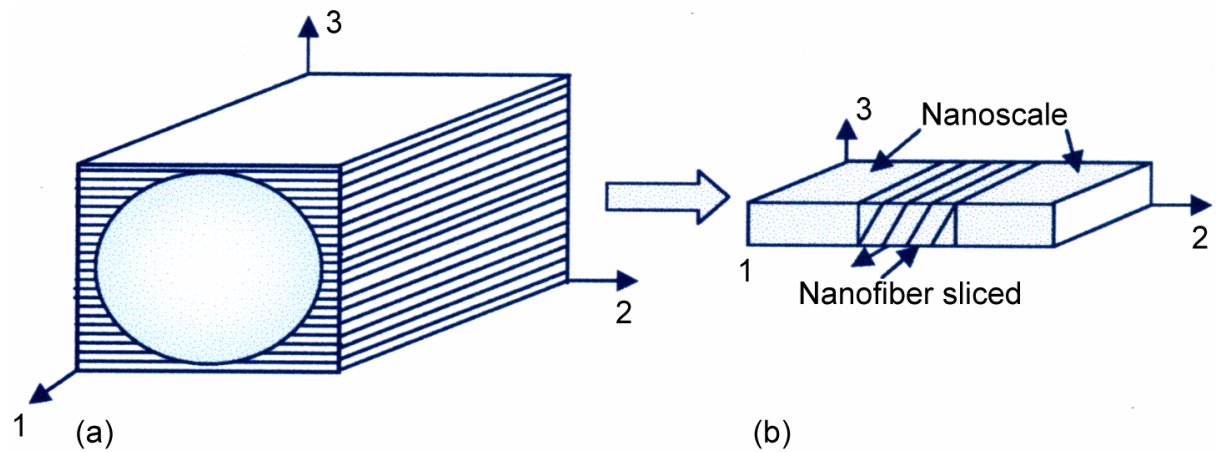

Figure 4.-Nanofiber substructuring. (a) Several slices through the thickness.

(b) Nanofiber sliced.

nanosubply with its corresponding stresses is shown in figure 5. All the nanomechanics predictive equations are derived by using figure 5 . The equations used are extensive; they are all programmed in ICAN/JAVA (ref. 10). Details are not explicitly shown here because the emphasis is on the results obtained and their practical significance. A simplified form of the equation is summarized prior to predicted results. The equations are for (1) In situ nanofabrication parameters-fiber volume ratio, matrix volume ratio, and void volume ratio; (2) Nanophysical properties - density, heat capacity, heat conductivities, diffusivities, moisture expansion coefficients, and thermal expansion coefficients; (3) Mechanical properties - normal moduli, shear moduli, and Poisson's ratios; and (4) Individual uniaxial strengths, as shown in figure 5 . As previously mentioned, all these equations are programmed in ICAN/JAVA and are available for obtaining the results that are subsequently described. This approach has the unique advantage that it can be used directly to predict nano, micro, macro, and structural properties of composites as required in item 7 of reference 12 . 


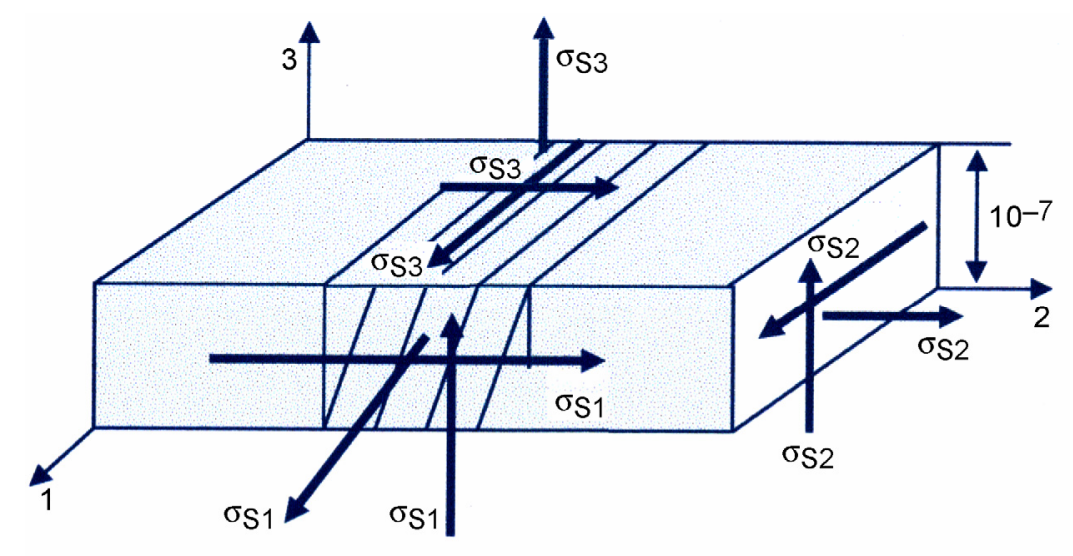

Figure 5.-Nanostresses on a nanosubply (units are in inches).

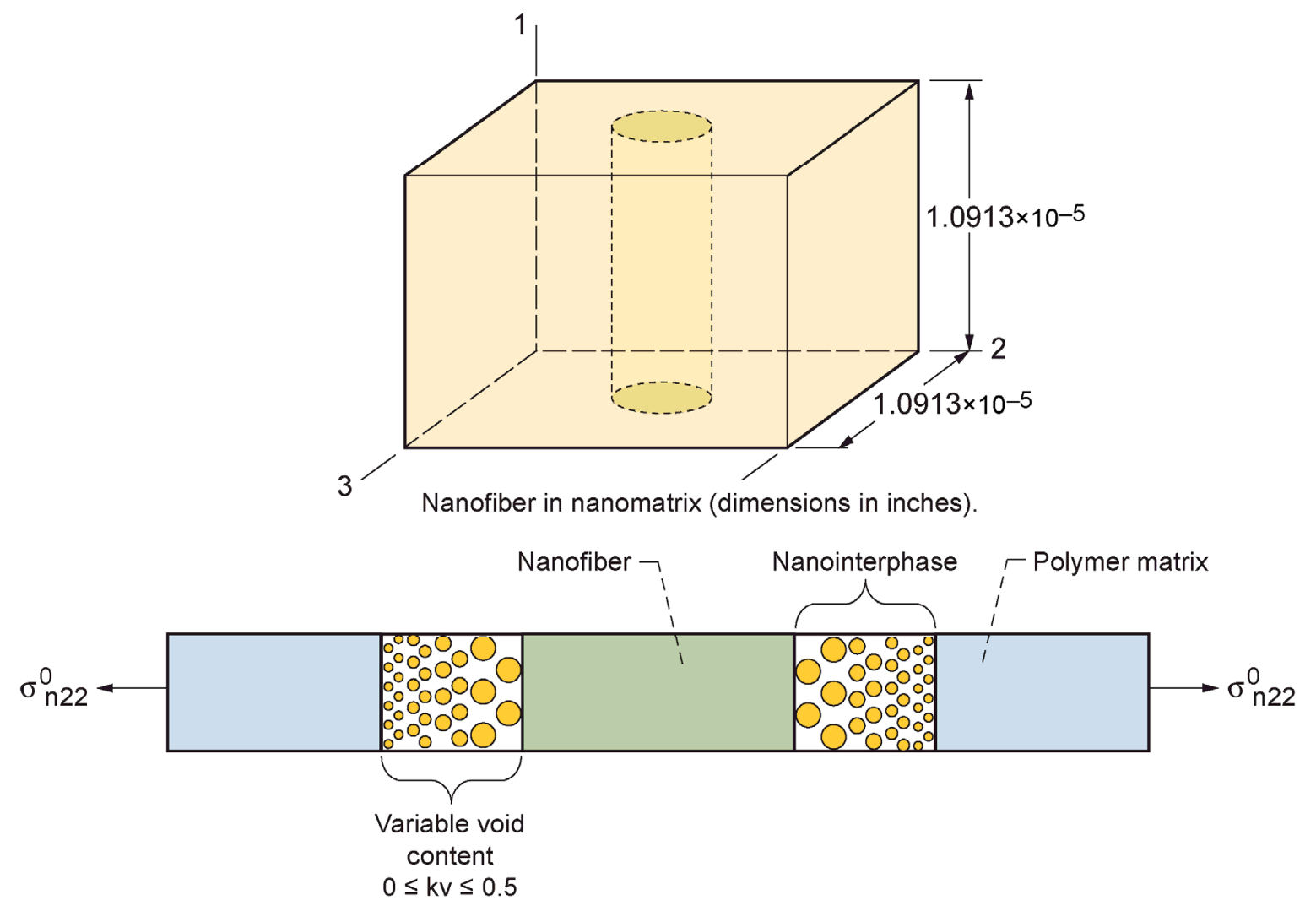

Figure 6.-Vertical section of a composite nanocell through nanofiber center.

Prior to describing the results obtained, it is instructive to describe the interface and how it is modeled. The schematics in figure 6 show a vertical slice with unit thickness of the nanocomposite with a single fiber in it. As can be seen in this slice, the fiber interface is represented by a series of progressively larger volume voids starting with the smallest near the matrix interface and ending with the fiber interface. It can be visualized by cutting a vertical section through and part in the interface that the resisting force will be equal to the applied force. However, the stress in the matrix will be magnified because of the voids. This magnification is shown in figure 7 for a specific nanocomposite with 0.05 -fiber volume ratio and with void volume ratio varying from 0.05 to 0.4 . 


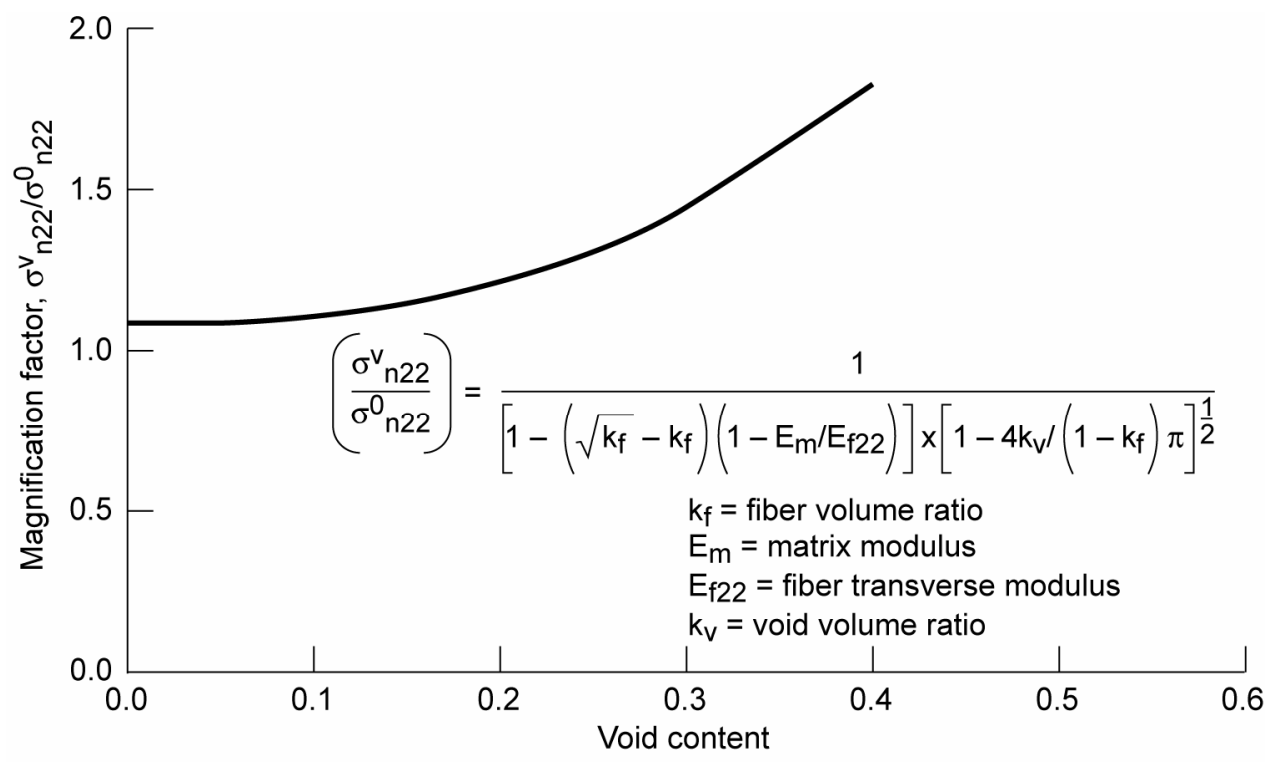

Figure 7.-Nanocomposite magnification factor.

The results that will be presented are based on a typical composite for structural application. That is, the fiber volume ratio is assumed to be 0.05 and a monofiber ply thickness of $7 \times 10^{-5}$ in. thick. The number of nanofibers of diameter of $2.756 \times 10^{-6}$ in. to fill a ply thickness of 0.005 in. thick by 1 in. wide with a volume ratio of 0.05 (typical of fiber nanocomposites) is about $42 \times 10^{6}$, a large number. However, when those numbers become practical, the herein described procedure to predict the respective properties will be available.

\section{Results and Discussion}

The results obtained are by assuming there is no interphase and are discussed in the following order: (1) in situ fabrication parameters; (2) physical variables; (3) mechanical variables; and (4) individual uniaxial strengths.

\section{In Situ Fabrication Parameters}

The in situ fabrication parameters include the fiber volume ratio, the matrix volume ratio, and the voids volume ratio. The equations used for these parameters are summarized in figure 8 . The in situ fiber volume ratio is graphically plotted through the nanoply thickness in figure 9 . As can be seen, it starts at zero and rises up to 0.25 . The fiber volume ratio distribution illustrated in figure 9 is a result of the substructuring of the single fiber into 10 subslices. The practical significance of that distribution is that the damage will most probably initiate at the center of the laminate. Figure 9 is also instructive in interpreting the input fiber volume ratio of 0.05 , which shows that the in situ fiber volume ratio will be a weighted average compared to its through-the-thickness distribution.

The in situ matrix volume ratio is shown graphically in figure 10. Its distribution through the nanolaminate thickness is the complement of the in situ fiber volume ratio. It starts at 1.0, at the matrix region, and decreases progressively to about 0.75 at the center. This very small amount of matrix volume ratio will definitely cause stress risers at this point and damage to initiate. It is also interesting to note that the average matrix volume ratio of 0.95 is a weighted average through the thickness as can be deduced from figure 10. Because the two distributions are complementary, the sum of the two must equal one at 
any one-fiber/matrix volume ratio in the absence of voids. These plots are presented here to illustrate their variation through the thickness of a single-ply nanocomposite.

The void volume ratio is plotted in figure 11 . Note that the void volume ratio is constant through the thickness. It is constant because it is assumed in the theoretical development that in each slice the void volume ratio is a constant, which is the input value and that the properties are predicted for one void volume ratio which is " 0 ."

$$
\begin{aligned}
& k_{f}+k_{m}+k_{v}=1 \\
& \text { Partial volumes: } \\
& \text { Ply density: } \\
& \rho_{\ell}=k_{f} \rho_{f}+k_{m} \rho_{m} \\
& \text { Resin volume ratio: } \\
& k_{m}=\left(1-k_{v}\right) /\left[1+\left(\rho_{m} / \rho_{f}\right)\left(1 / \lambda_{m}-1\right)\right] \\
& k_{f}=\left(1-k_{v}\right) /\left[1+\left(\rho_{f} / \rho_{m}\right)\left(1 / \lambda_{f}-1\right)\right] \\
& \lambda_{f}+\lambda_{m}=1 \\
& t_{\ell}=1 / 2 N_{f} d_{f} \sqrt{\pi / k_{f}} \\
& \delta_{\ell}=1 / 2\left[\sqrt{\pi / k_{f}}-2\right] d_{f} \\
& \delta_{s}=\delta_{\ell} \\
& k_{f}=\pi / 4 \sim 0.785
\end{aligned}
$$$$
\operatorname{Ply}(\ell) \frac{r \text { Void }\left(k_{v}\right)}{\operatorname{Matrix}(m)-!}
$$
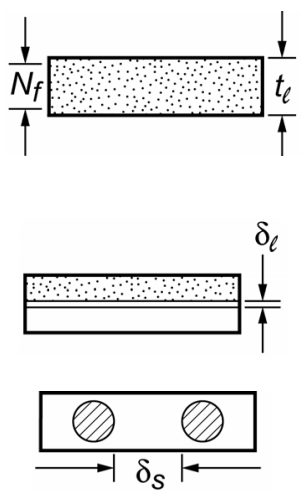

Figure 8.-Micromechanics and geometric relationships.

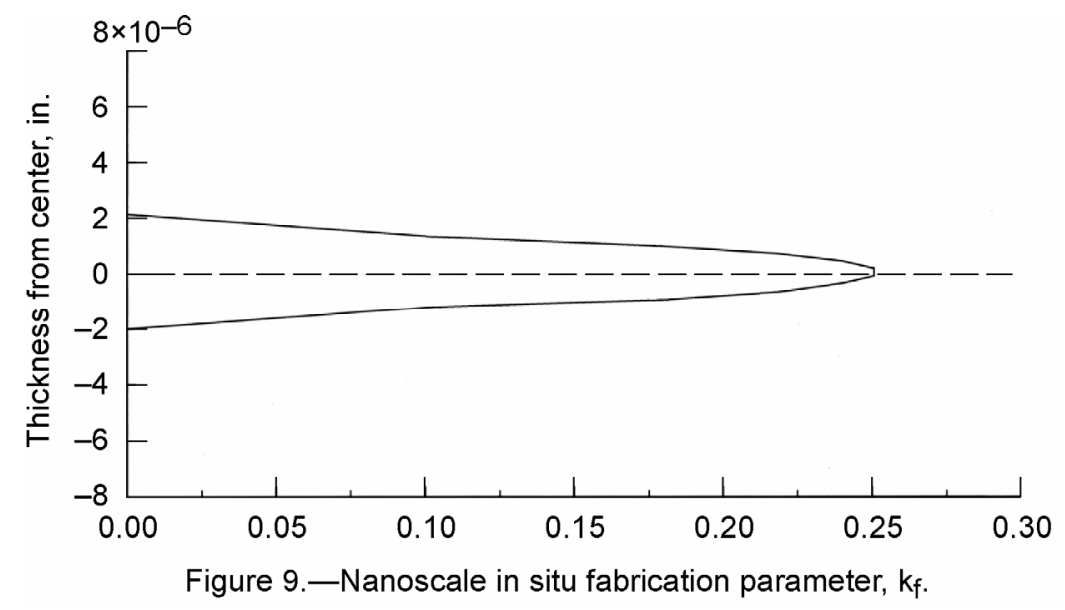



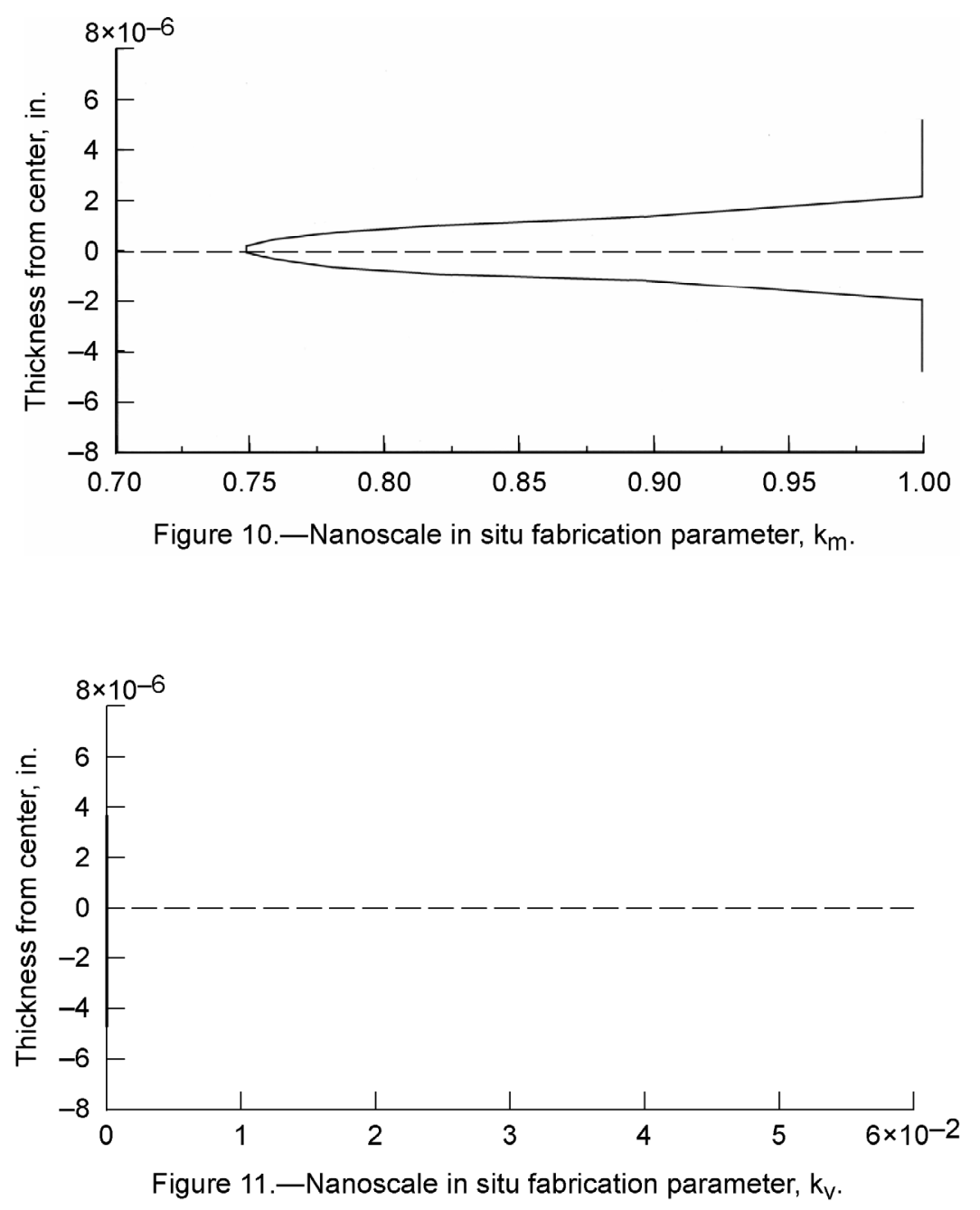

\section{Physical Properties}

The equations for predicting these properties are summarized in figure 12 except the equation for the weight density, which is the second equation in figure 8 . The first physical property of a nanocomposite is the weight density whose distribution through the thickness is plotted in figure 13. It is noted that this physical property has analogous distribution as that for the fiber volume ratio. It starts at the weight density of the matrix and progresses to its highest value at midheight. The second physical property investigated is the heat capacity, which is plotted in figure 14 through the thickness. This property behaves opposite to that of the density - starts at the heat capacity of the resin and decreases progressively at midheight. This is so because the heat capacity of the resin is greater than that of the fiber $(0.25$ to $\left.0.23 \mathrm{Btu} / \mathrm{lb}-{ }^{\circ} \mathrm{F}\right)$. This is the last of the scalar properties. The subsequent ones are directional. The major observation to be made about the scalar properties is that they all have about the same shape except the voids where their distribution is constant through the thickness of the nanolaminate. 
Heat capacity:

Longitudinal conductivity:

Transverse conductivity:

$$
K_{\ell 11}=k_{f} K_{f 11}+k_{m} K_{m}
$$

$$
C_{\ell}=\frac{1}{\rho_{\ell}}\left(k_{f} \rho_{f} C_{f}+k_{m} \rho_{m} C_{m}\right)
$$

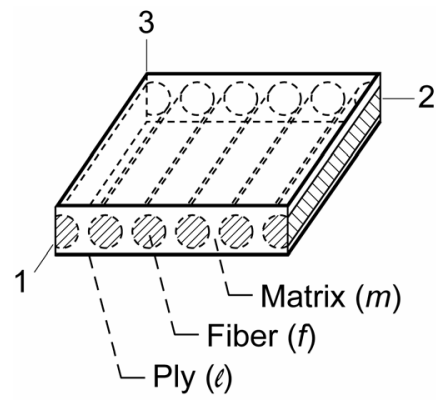

$$
K_{\ell 22}=\left(1-\sqrt{k_{f}}\right) K_{m}+\frac{K_{m} \sqrt{k_{f}}}{1-\sqrt{k_{f}}\left(1-K_{m} / K_{f 22}\right)}=K_{\ell 33}
$$

For voids:

$$
K_{m}=\left(1-\sqrt{k_{v}}\right) K_{m}+\frac{K_{m} \sqrt{k_{v}}}{1-\sqrt{k_{v}}\left(1-K_{m} / K_{v}\right)}
$$

Longitudinal thermal expansion coefficient:

$$
\alpha_{\ell 11}=\frac{k_{f} \alpha_{f 11} E_{f 11}+k_{m} \alpha_{m} E_{m}}{E_{\ell 11}}
$$

Transverse thermal expansion coefficient:

Figure 12.-Composite micromechanics and thermal properties.

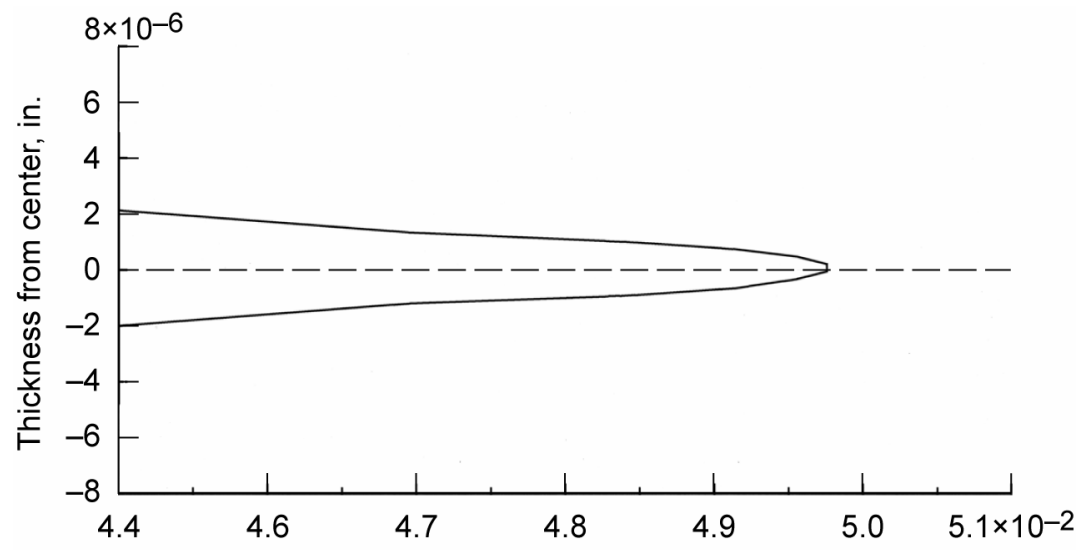

Figure 13.-Nanoscale physical parameter density, $\rho_{\ell}$ (lb/in. $\left.{ }^{3}\right)$.

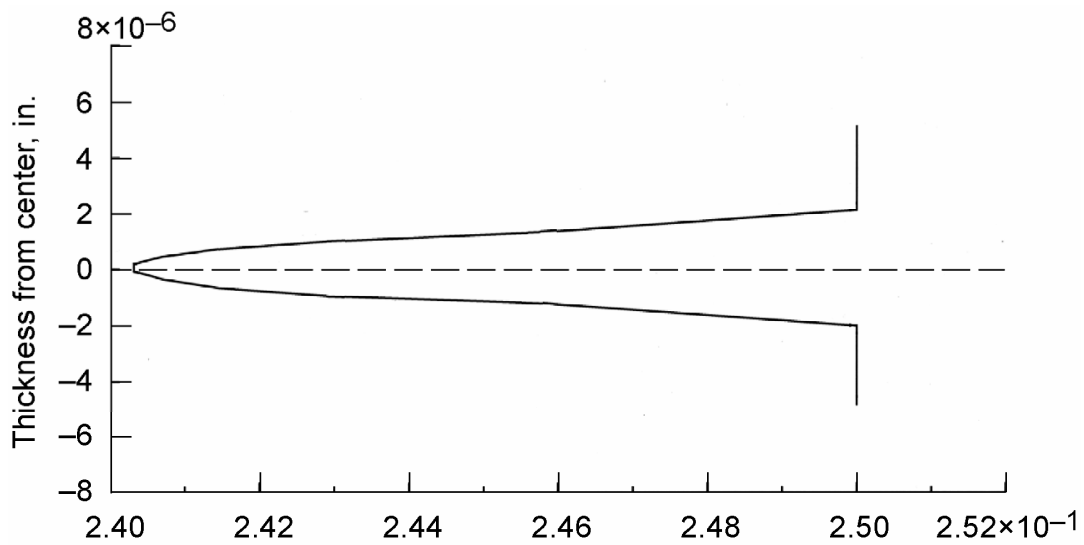

Figure 14.-Nanoscale physical parameter heat capacity, $\mathrm{H}_{\mathrm{C}}\left(\mathrm{Btu} / \mathrm{lb}-{ }^{\circ} \mathrm{F}\right)$. 


\section{Heat Conductivities}

The longitudinal heat conductivity is plotted in figure 15 . The variation is similar to the scalar properties. It starts at the matrix conductivity and it increases progressively to the midheight of the nanolaminate, and then decreases symmetrically to the conductivity of the matrix. The transverse heat conductivity is shown graphically in figure 16. It can be seen that this one has the same shape as the longitudinal, but much smaller scale. The heat conductivity in the third direction has the same distribution as that in the transverse.

\section{Diffusivities}

The equations used for these properties are summarized in figure 17. The longitudinal moisture diffusivity for the nanocomposite is plotted in figure 18. It can be seen in the figure that the longitudinal diffusivity curve is analogous to the matrix volume ratio curve, which is a maximum in the matrix region and decreases continuously to the midheight where it attains its least value. This is because moisture does not diffuse through the fibers. The transverse diffusivity is plotted in figure 19. It has approximately the same shape as the longitudinal, but it is longer and reaches lower value at midheight about $0.9 \times 10^{-7}$ to about $2.2 \times 10^{-7}$. Through-the-thickness diffusivity is the same as the transverse.

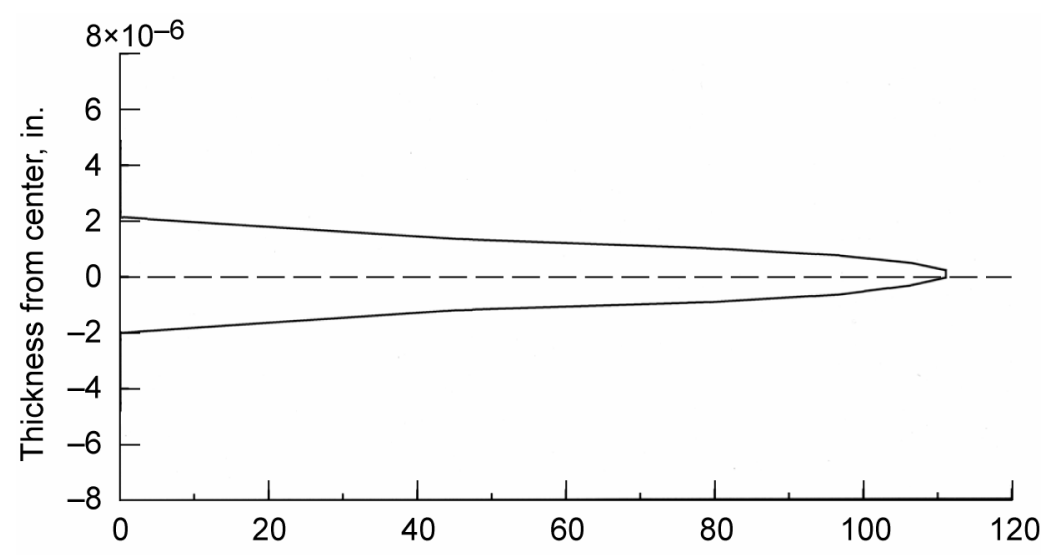

Figure 15.-Nanoscale physical variable longitudinal heat conductivity, $\mathrm{K}_{\ell 11}$ (Btu/hr/ft2/\%F/in.).

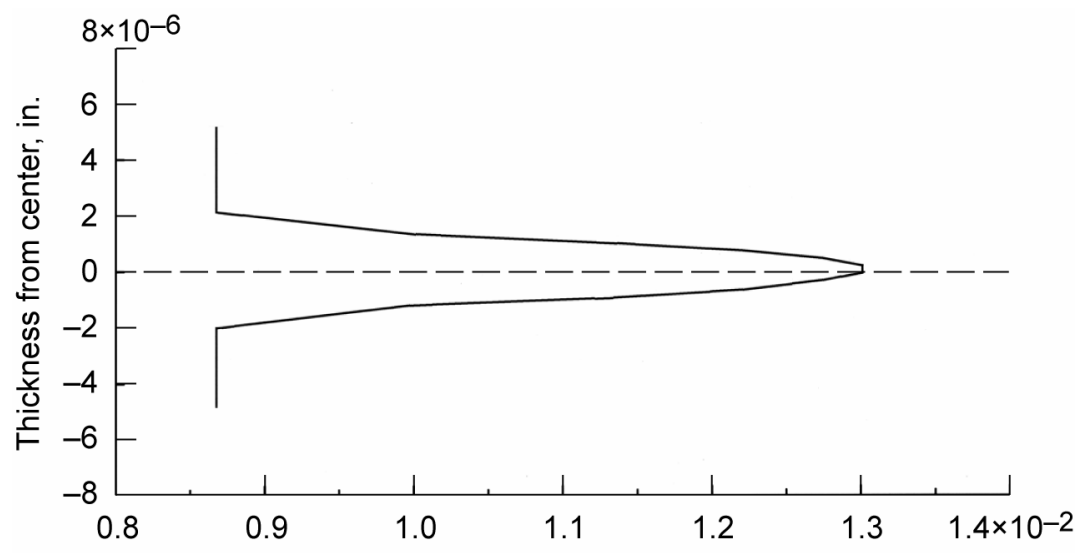

Figure 16.-Nanoscale physical variable transverse heat conductivity, $\mathrm{K}_{\mathrm{e} 22}\left(\mathrm{Btu} / \mathrm{hr} / \mathrm{ft} 2{ }^{\circ} \mathrm{F} / \mathrm{in}.\right)$. 
Longitudinal diffusivity:

Transverse diffusivity:

Longitudinal moisture expansion coefficient:

Transverse moisture expansion coefficient: $\quad \beta_{\ell 22}=\beta_{m}\left(1-\sqrt{k_{f}}\right)\left[1+\frac{\sqrt{k_{f}}\left(1-\sqrt{k_{f}}\right) E_{m}}{\sqrt{k_{f}} E_{\ell 22}+\left(1-\sqrt{k_{f}}\right) E_{m}}\right]=\beta_{\ell 33}$

For incompressible matrix:

$$
\begin{aligned}
& D_{\ell 11}=\left(1-k_{f}\right) D_{m} \\
& D_{\ell 22}=\left(1-\sqrt{k_{f}}\right) D_{m}=D_{\ell 33} \\
& \beta_{\ell 11}=\beta_{m}\left(1-k_{f}\right) E_{m} / E_{\ell 11} \\
& \text { ᄂ } \\
& \beta_{\ell 11}=0 \\
& \beta_{\ell 22}=\beta_{m} \rho_{\ell} / 2 \rho_{m}=\beta_{\ell 33}
\end{aligned}
$$

Figure 17.-Composite micromechanics and hygro properties.

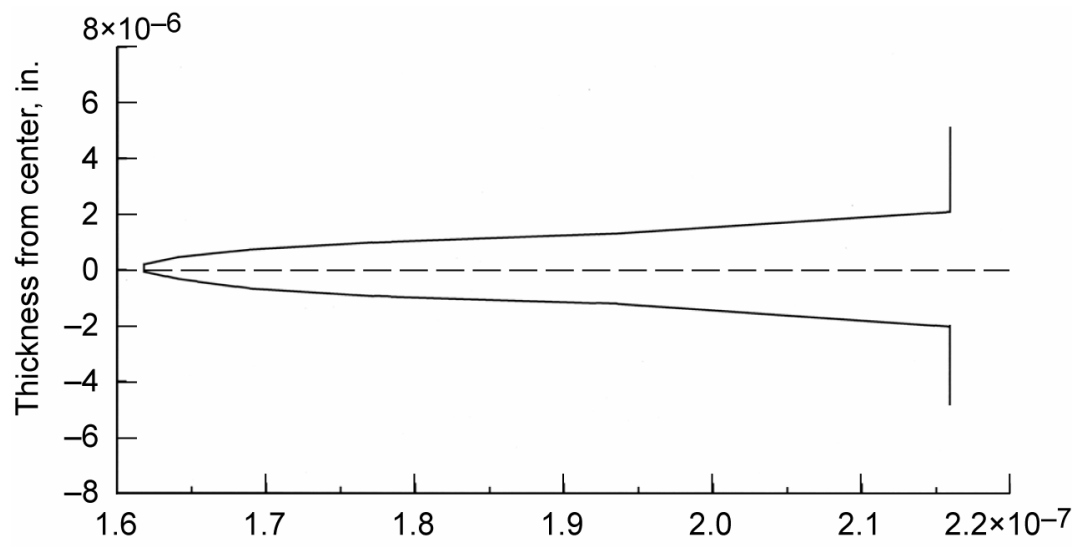

Figure 18.-Nanoscale physical variable longitudinal moisture diffusivity, $\mathrm{D}_{\mathrm{e} 11}$ (in. $2 / \mathrm{hr}$ ).

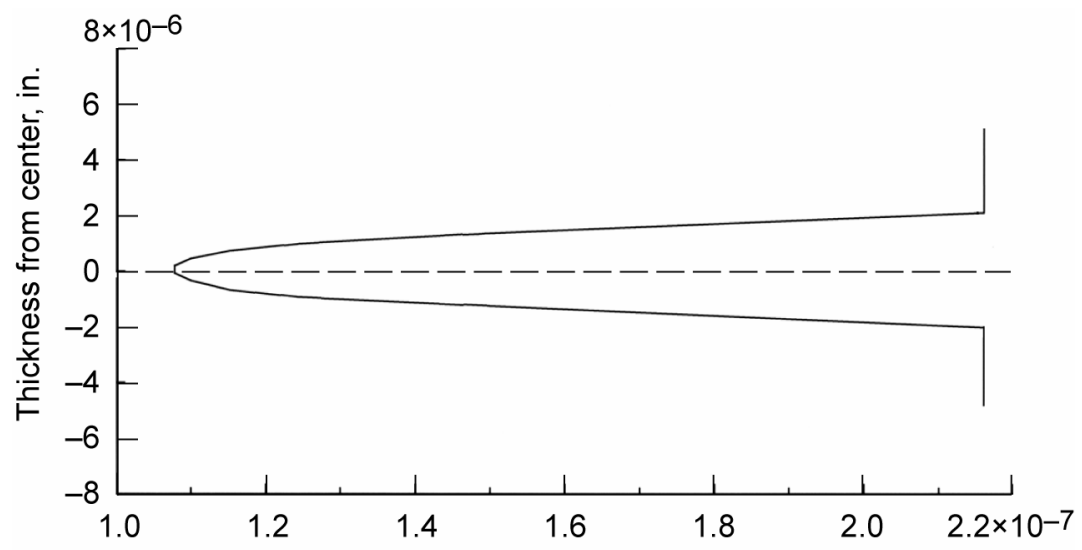

Figure 19.-Nanoscale physical variable transverse moisture diffusivity, $\mathrm{D}_{\ell 22}$ (in. $2 / \mathrm{hr}$ ). 


\section{Moisture Expansion}

The longitudinal moisture expansion coefficient is shown graphically in figure 20. As can be seen in figure 20, it starts at a relatively high matrix expansion and decreases rapidly to almost zero values. The reason for this rapid decrease is that the fibers do not expand in moisture fields. The weighted average of the longitudinal moisture expansion is near zero, thus exhibiting a huge stress concentration in the bounding matrix. The practical significance of this large discrepancy between the matrix and fiber moisture expansion is that moisture will induce nanoscale crazes in the matrix in that region.

The transverse moisture expansion is plotted in figure 21. It can be seen in this figure that its behavior is analogous to the longitudinal diffusivity.

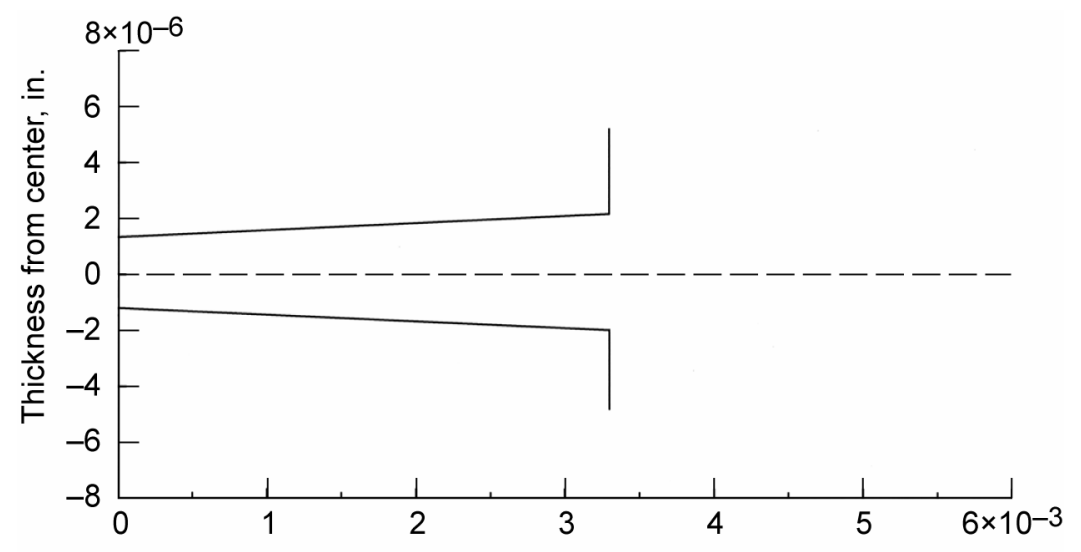

Figure 20.-Nanoscale physical variable longitudinal moisture expansion, $\beta_{\ell 11}$ (in./in./\%M).

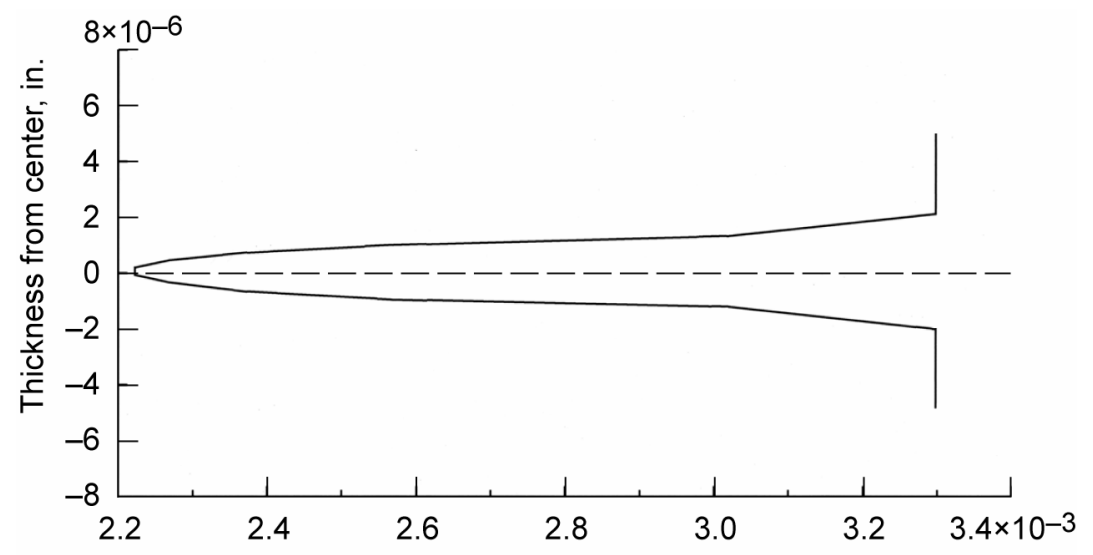

Figure 21.-Nanoscale physical variable transverse moisture expansion, $\beta_{\ell 22}$ (in./in./\%M). 


\section{Thermal Expansion}

The longitudinal nanothermal expansion coefficient is shown graphically in figure 22 . This coefficient shows the same behavior as the longitudinal moisture expansion but at different scales. It starts with the thermal expansion of the matrix and rapidly decreases to near zero. The reason for this rapid decrease from the matrix to the fiber is that the fibers are assumed to have a near-negative longitudinal expansion. The comments noted in the discussion of the longitudinal moisture expansion, with respect to stress concentration, apply to the thermal longitudinal expansion as well. The practical significance is that crazes in this matrix region will occur during the cooling down of the nanocomposite.

The transverse thermal expansion is plotted in figure 23. It shows similar behavior as that for the transverse moisture expansion in figure 21. As can be seen, it exhibits a gradual decrease from the matrix region to the fiber reaching a minimum at midheight. It is noted here, as a reminder, that the distribution shown in these figures are the direct result of the progressive monofiber laminate substructuring. It is also noted that the through-the-thickness thermal expansion is the same as that for the transverse. This property is the last one of the physical properties of the nanounidirectional laminate.

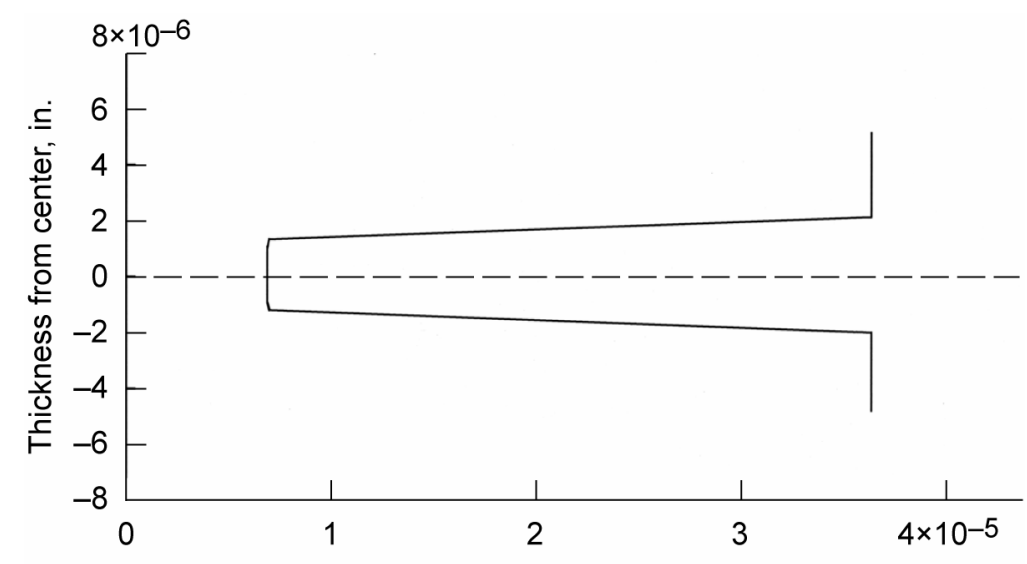

Figure 22.-Nanoscale physical variable longitudinal thermal expansion, $\alpha_{\ell 11}$ (in./in. $\left./{ }^{\circ} \mathrm{F}\right)$.

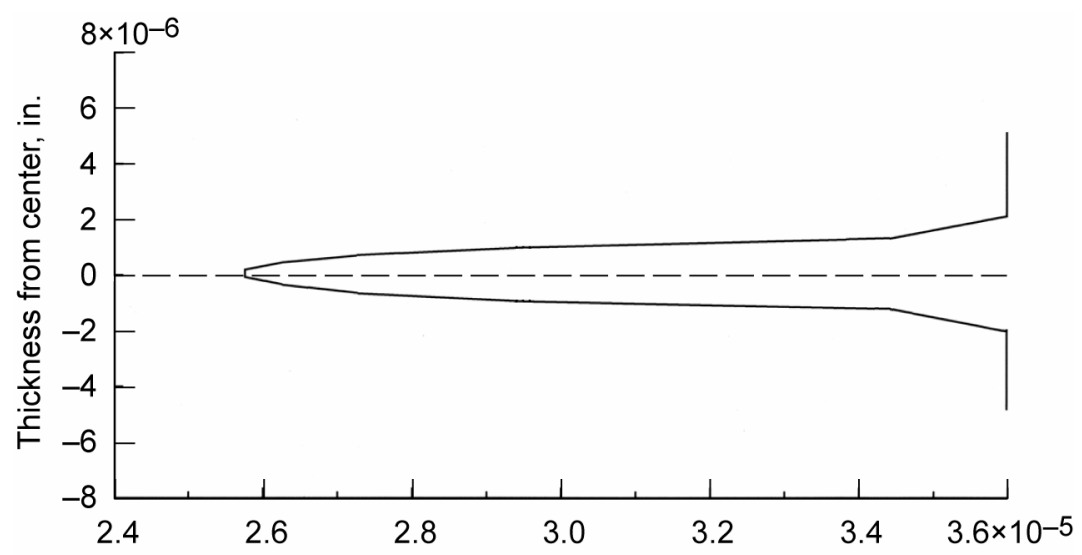

Figure 23.-Nanoscale physical variable transverse thermal expansion, $\alpha_{\ell 22}$ (in./in. $/{ }^{\circ} \mathrm{F}$ ). 


\section{Mechanical Properties}

These properties include all the information that is needed to perform a stress and or displacement analyses. Included are moduli, Poisson's ratio, and uniaxial strengths as described below.

\section{Moduli}

The equations used for these properties are summarized in figure 24. The longitudinal modulus is shown graphically in figure 25 . The graph starts with the matrix modulus, which is relatively low in the scale of the abscissa. It increases gradually to its maximum value at midheight and it is symmetric as would be expected. Note that the highest value is close to $2.5 \times 10^{8} \mathrm{psi}$, which is at about 0.25 of the fiber volume ratio for a fiber whose modulus is $1.0 \times 10^{9} \mathrm{psi}$.

The transverse modulus is plotted in figure 26. This value starts at the matrix value and increases gradually to its maximum value at midheight. Note that the maximum value for this modulus is about $1.0 \times 10^{6} \mathrm{psi}$. This low value results from the very low fiber volume ratio $(0.05)$. The important point here is that this nanocomposite is highly anisotropic at about $250 / 1$.

The in-plane shear modulus is plotted graphically in figure 27. This plot is analogous to the transverse modulus but one-third the scale in the abscissa. It reaches its maximum value at midheight by increasing gradually from the matrix shear modulus to that value. One observation is that the transverse and shear moduli are matrix-controlled quantities and their respective nanocomposite values are expected to be low.

The through-the-thickness shear modulus is plotted graphically in figure 28 . It is the same as the inplane shear modulus. The reason is that they are both matrix dependent and the fiber shear moduli are relatively low.

Longitudinal modulus:

Transverse modulus:

Shear modulus:

Shear modulus:

Poisson's ratio:

Poisson's ratio:

$$
E_{\ell 11}=k_{f} E_{f 11}+k_{m} E_{m}
$$

$$
E_{\ell 22}=\frac{E_{m}}{1-\sqrt{k_{f}}\left(1-E_{m} / E_{f 22}\right)}=E_{\ell 33}
$$

$$
G_{\ell 12}=\frac{G_{m}}{1-\sqrt{k_{f}\left(1-G_{m} / G_{f 12}\right)}}=G_{\ell 13}
$$

$$
G_{\ell 23}=\frac{G_{m}}{1-\sqrt{k_{f}\left(1-G_{m} / G_{f 23}\right)}}
$$$$
v_{\ell 12}=k_{f} v_{f 12}+k_{m} v_{m}=v_{\ell 13}
$$

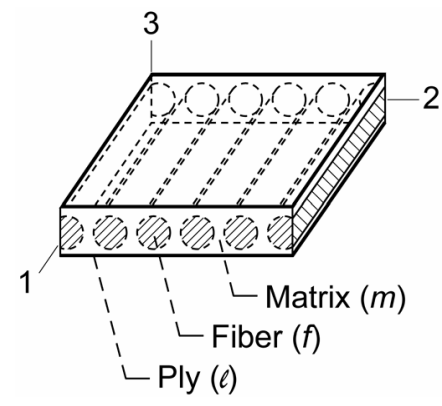

$$
v_{\ell 23}=\frac{E_{\ell 22}}{2 G_{\ell 23}}-1
$$

Figure 24.-Composite micromechanics and mechanical properties. 


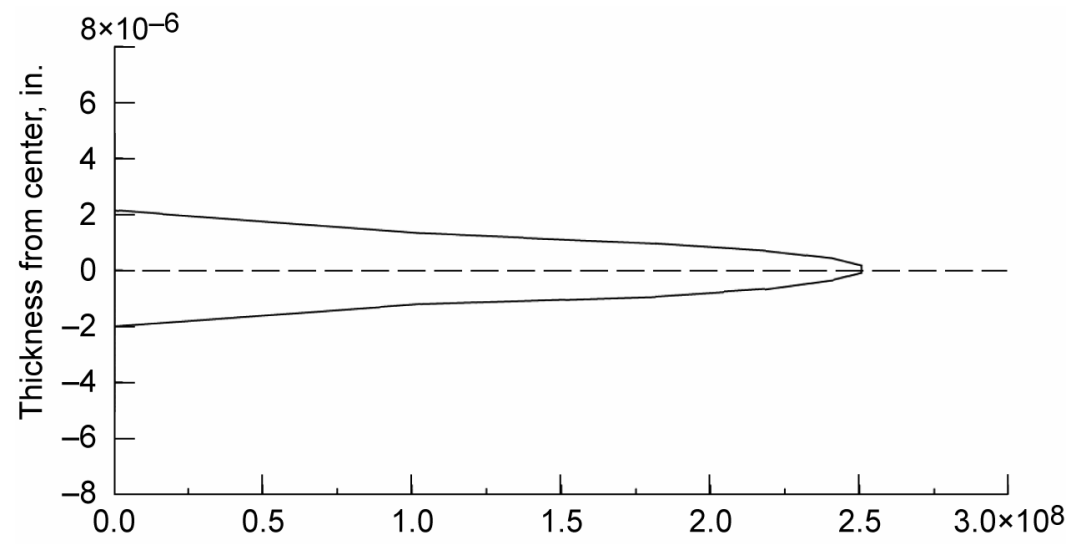

Figure 25.-Nanoscale mechanical property variable longitudinal modulus, $\mathrm{E}_{\ell 11}\left(\mathrm{lb} / \mathrm{in} .{ }^{2}\right)$.

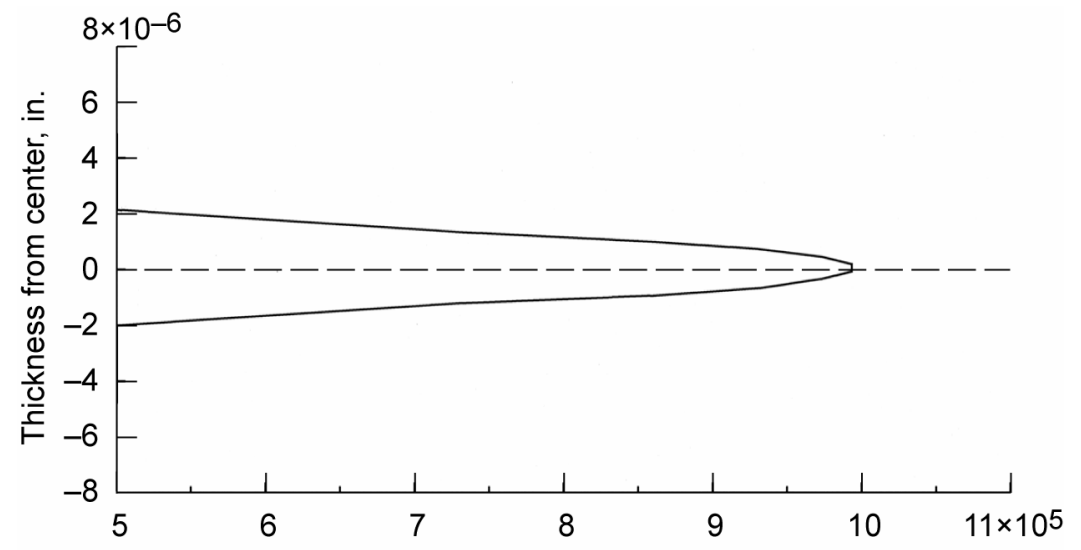

Figure 26.-Nanoscale mechanical property variable transverse modulus, $\mathrm{E}_{\ell 22}\left(\mathrm{lb} / \mathrm{in} .{ }^{2}\right)$.

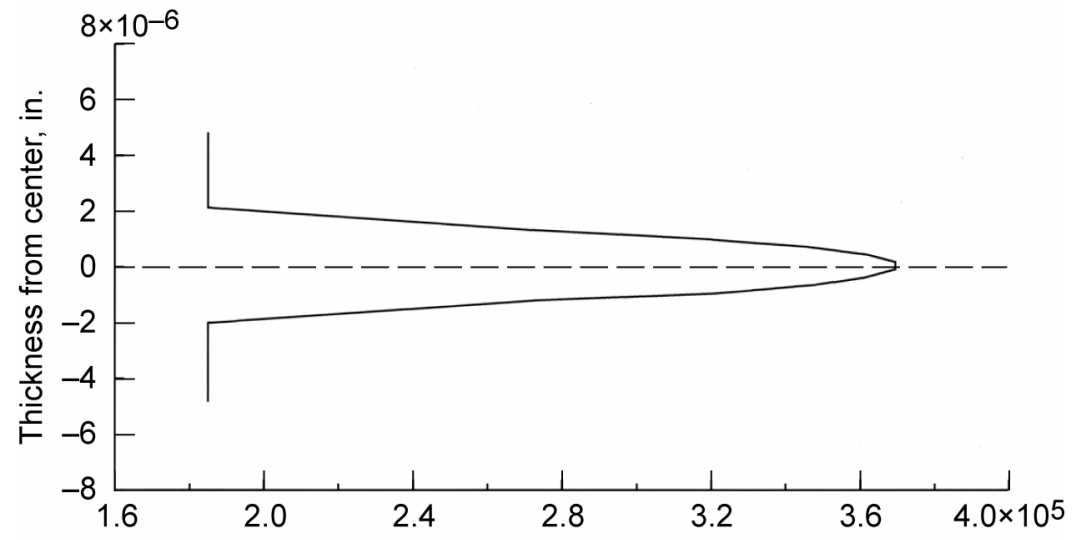

Figure 27.-Nanoscale mechanical property shear modulus, $\mathrm{G}_{\ell 12}$ (lb/in. ${ }^{2}$ ). 


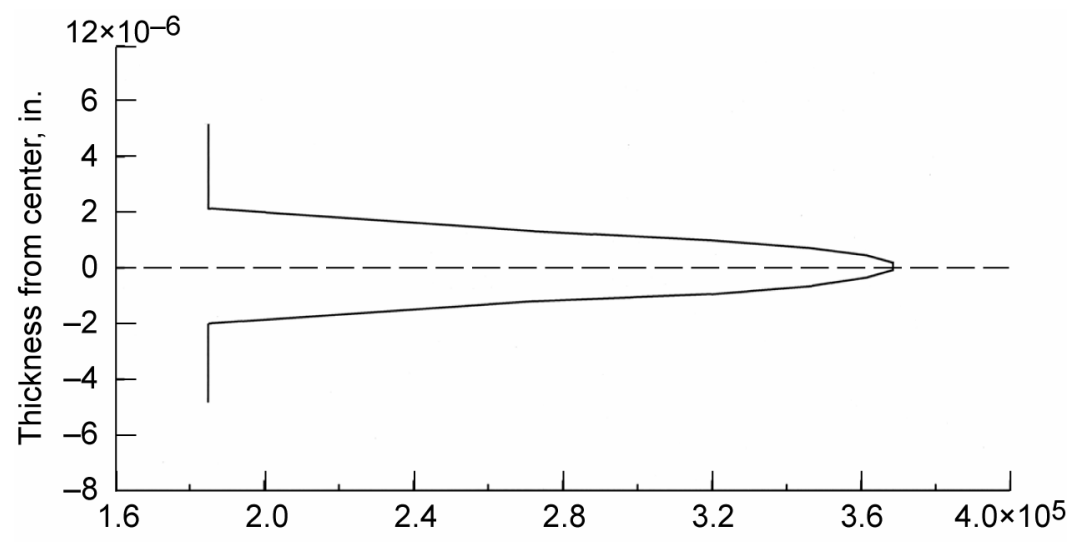

Figure 28.-Nanoscale mechanical property, $\mathrm{G}_{\mathrm{C23}}\left(\mathrm{lb} / \mathrm{in}^{2}{ }^{2}\right)$.

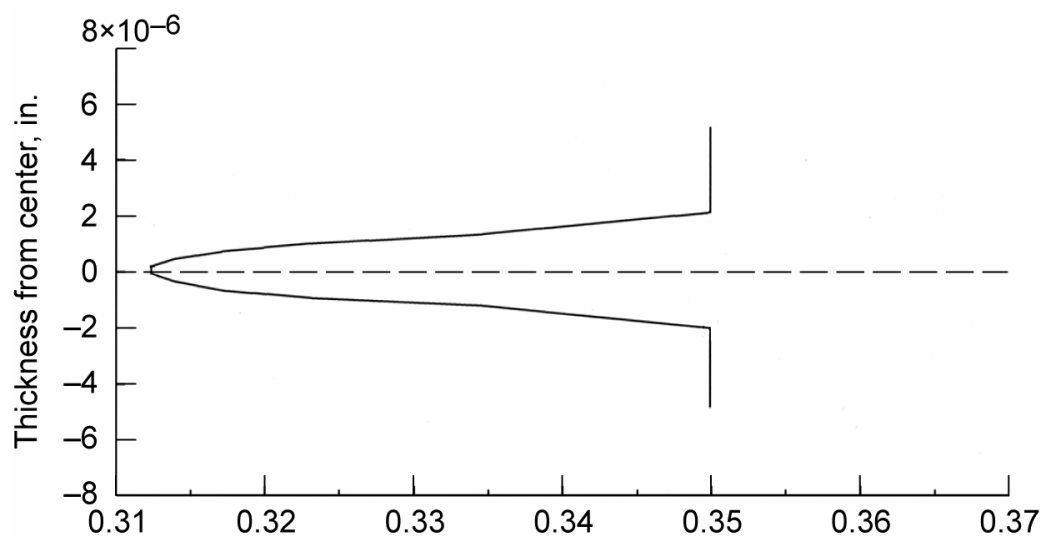

Figure 29.-Nanoscale mechanical property Poisson's ratio, $v_{\ell 12}$ (in./in.).

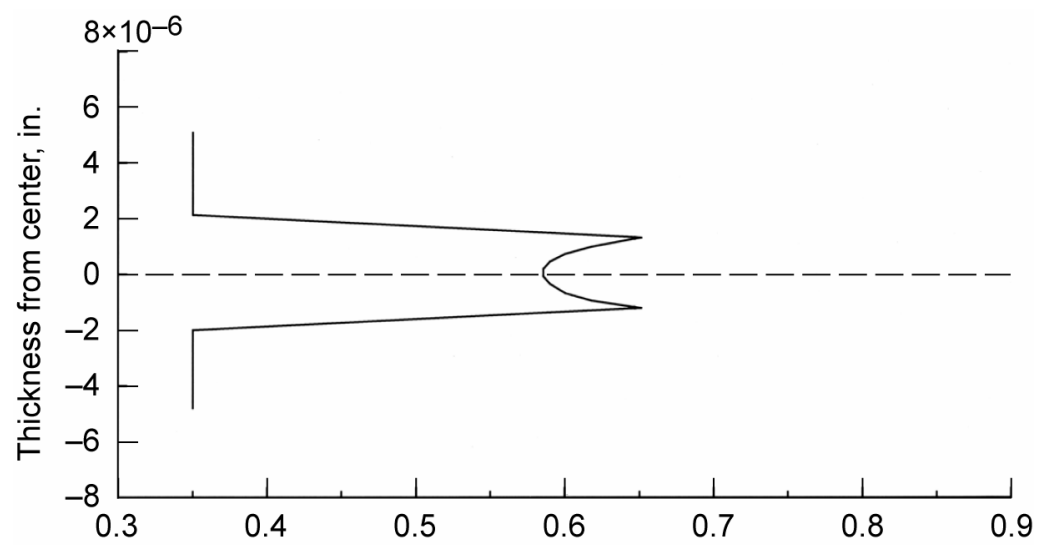

Figure 30.-Nanoscale mechanical property Poisson's ratio, $v_{\ell 23}$ (in./in.).

\section{Poisson's Ratios}

The major Poisson's ratio is plotted in figure 29. It can be seen that it starts at its maximum value (the average value at 0.05 fiber volume ratio) and decreases gradually reaching its minimum value of about 0.29 at midheight. It can also be observed that the graph is a well-behaved function.

The through-the-thickness Poisson's ratio is plotted graphically in figure 30. Observe that this is a peculiar plot. It starts from an average value of the Poisson's ratio of the matrix, rapidly increases to point 0.651 and then progressively decreases to a lower value of about 0.58 at midheight, and it is symmetric. 
The only explanation at this time is that the restraints of the substructured layers at the nanoscale cause this bimodal behavior. This is the last moduli property of the mechanical properties of a unidirectional nanolaminate.

\section{Uniaxial Nanocomposite Strengths}

The equations used for predicting these properties are summarized in figure 31 . The uniaxial strengths of interest in nanocomposite designs are longitudinal tension and compression, transverse tension and compression, in-plane shear, and through-the-thickness shear. Below each of these is discussed in some detail.

\section{Longitudinal Tension}

The longitudinal tensile strength is plotted graphically in figure 32 . The plot is symmetric about the midheight and it is analogous to that of the longitudinal modulus (fig. 25). The fiber strength of course is about three orders of magnitude less. It is observed that this strength behaves normally. It starts at a strength compared to matrix (about $15 \mathrm{ksi}$ ) and increases gradually to its highest value (about $2.0 \times 10^{5} \mathrm{ksi}$ ) at midheight. This very high value for tensile strength results from an input value of $8 \times 10^{5}$ psi for the nanofiber.

1. Longitudinal tension:

2. Longitudinal compression:

Fiber compression:

Delamination/shear:

Microbuckling:

3. Transverse tension:

4. Transverse compression:

5. Intralaminar shear:

$$
\begin{gathered}
S_{\ell 12 S} \approx\left[1-\left(\sqrt{k_{f}}-k_{f}\right)\left(1-G_{m} / G_{f 12}\right)\right] S_{m S} \\
S_{m} \approx\left\{1-\left[4 k_{v} /\left(1-k_{f}\right) \pi\right]^{1 / 2}\right\} S_{m}
\end{gathered}
$$

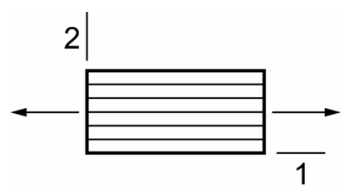

$$
S_{\ell 11 C} \approx k_{f} S_{f C}
$$

$$
S_{\ell 11 C} \approx 10 S_{\ell 12 S}+2.5 S_{m T}
$$$$
S_{\ell 11 C} \approx \frac{G_{m}}{1-k_{f}\left(1-\frac{G_{m}}{G_{f 12}}\right)}
$$
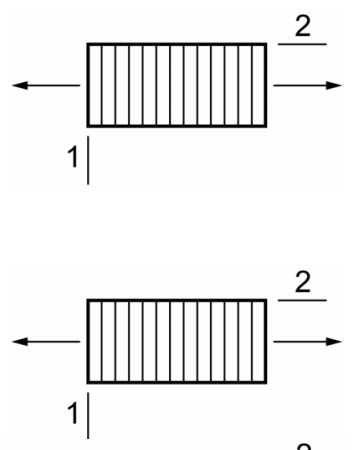

$$
S_{\ell 22 C} \approx\left[1-\left(\sqrt{k_{f}}-k_{f}\right)\left(1-E_{m} / E_{f 22}\right)\right] S_{m C}
$$
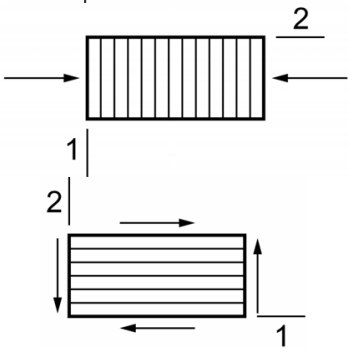

6. For voids:

Void -

Figure 31.-Composite micromechanics, uniaxial strengths, in-plane. 


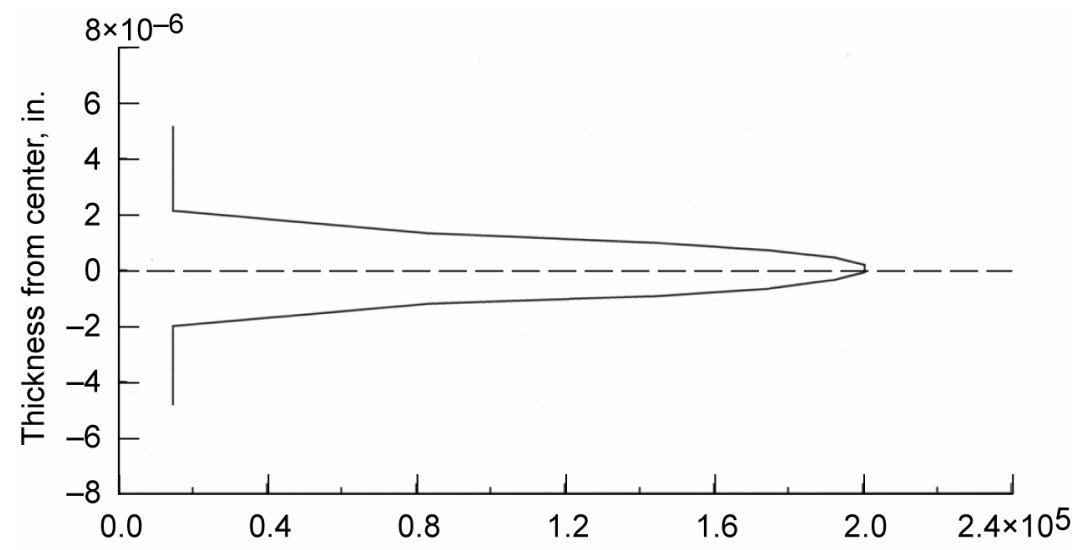

Figure 32.-Nanoscale uniaxial longitudinal tensile strength, $\mathrm{S}_{\ell 11 \mathrm{~T}}\left(\mathrm{lb} / \mathrm{in} .^{2}\right)$.

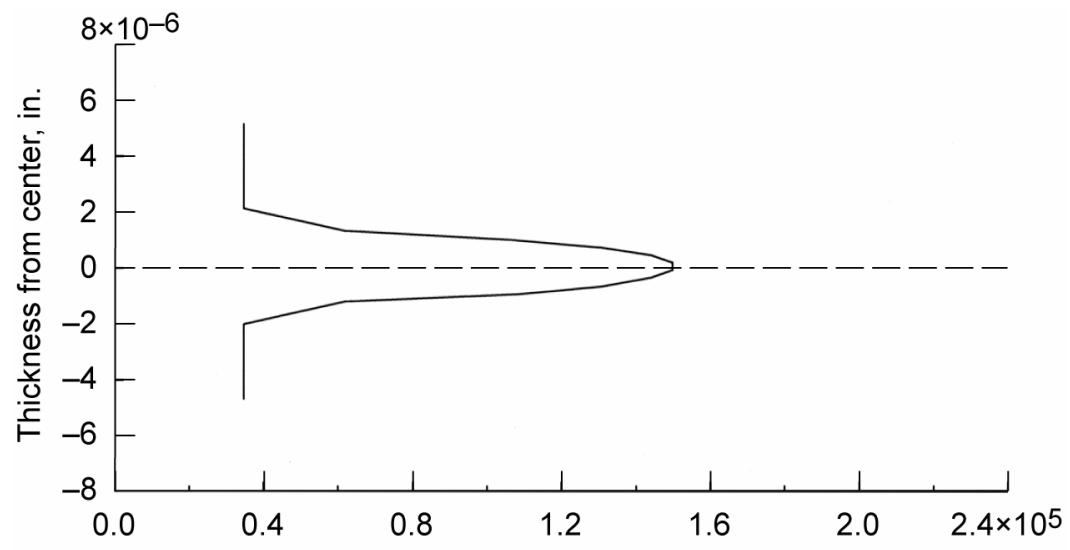

Figure 33.-Nanoscale uniaxial longitudinal compressive strength, $\mathrm{S}_{\ell 11 \mathrm{C}}\left(\mathrm{lb} / \mathrm{in} .^{2}\right)$.

\section{Longitudinal Compression}

The longitudinal compression strength is plotted graphically in figure 33. It starts at the matrix compressive strength (about $35 \mathrm{ksi}$ ) and increases rapidly to its highest value, which is about $160 \mathrm{ksi}$ at the midheight of the nanolaminate. Then it decreases symmetrically to about the compressive strength of the matrix.

\section{Transverse Tensile Strength}

The nanocomposite transverse strength of a unidirectional laminate is plotted graphically in figure 34 . As can be seen in the figure, it starts at the transverse tensile strength of the matrix, about $15000 \mathrm{psi}$ and decreases very rapidly to about $11300 \mathrm{psi}$ at the midheight of the nanolaminate. 


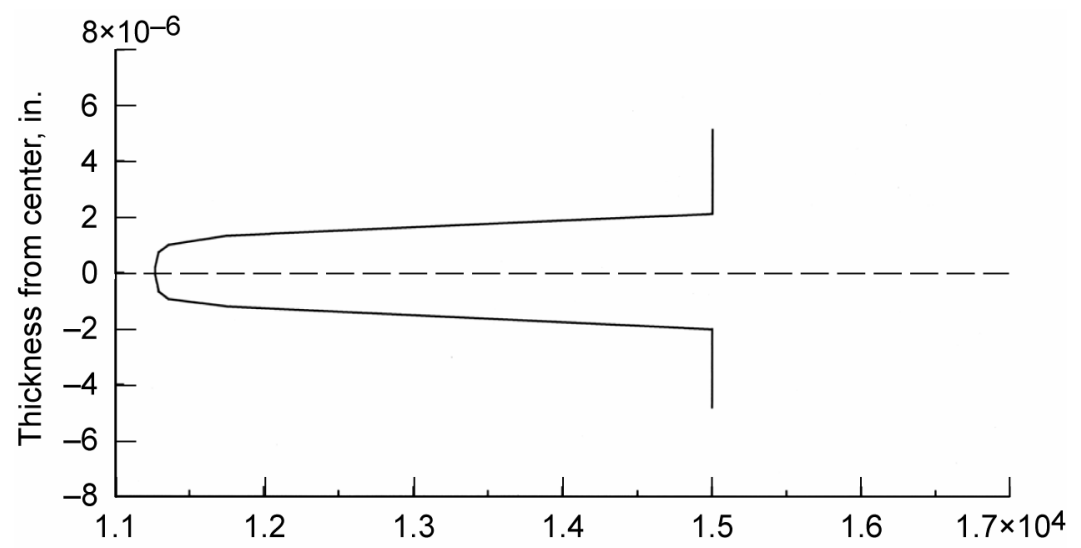

Figure 34.-Nanoscale uniaxial transverse tensile strength, $\mathrm{S}_{\ell 22 \mathrm{~T}}\left(\mathrm{lb} / \mathrm{in} .^{2}\right)$.

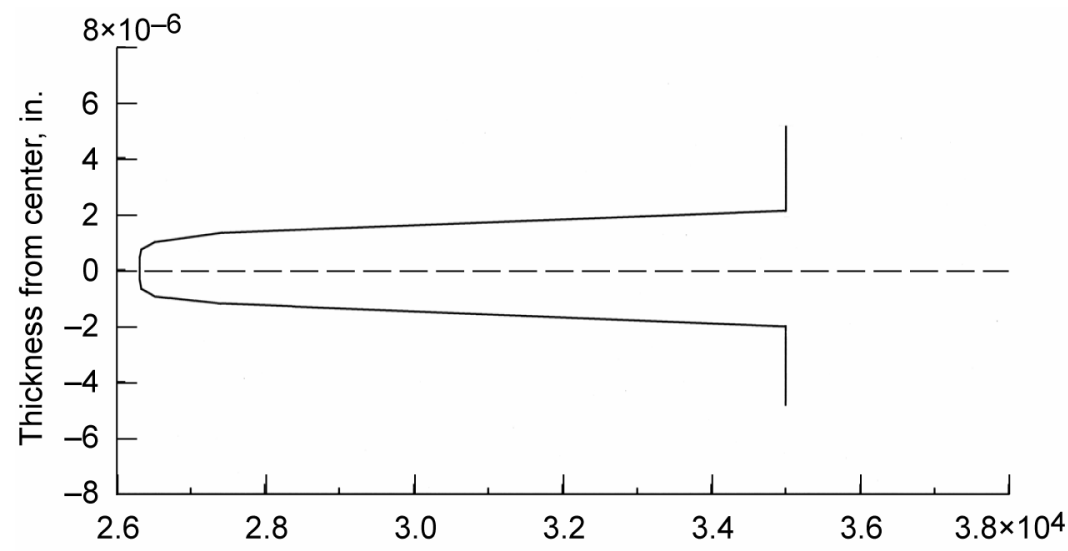

Figure 35.-Nanoscale uniaxial transverse compressive strength, $\mathrm{S}_{\mathrm{C22C}}\left(\mathrm{lb} / \mathrm{in}{ }^{2}\right)$.

\section{Transverse Compressive Strength}

The transverse compressive strength is shown graphically in figure 35 . The behavior of this strength is comparable to the transverse tensile strength (fig. 34). The comments made in that figure apply to this figure as well.

\section{Intralaminar Shear Strength}

The intralaminar shear strength is plotted graphically in figure 36 . The behavior of this strength is comparable to the two transverse strengths except that scale is a bit lower. The comments made for those two strengths apply to the intralaminar shear strength as well.

\section{Interlaminar Shear Strength}

The interlaminar (through-the-thickness) shear strength is plotted graphically in figure 37 . This strength has analogous behavior as the intralaminar shear strength except that it reaches about 10000 psi. Then it reverses symmetrically. The practical significance of this behavior is that the matrix-bounding interface needs to be very thin otherwise the unidirectional nanolaminate will have very little transverse and shear strengths. 


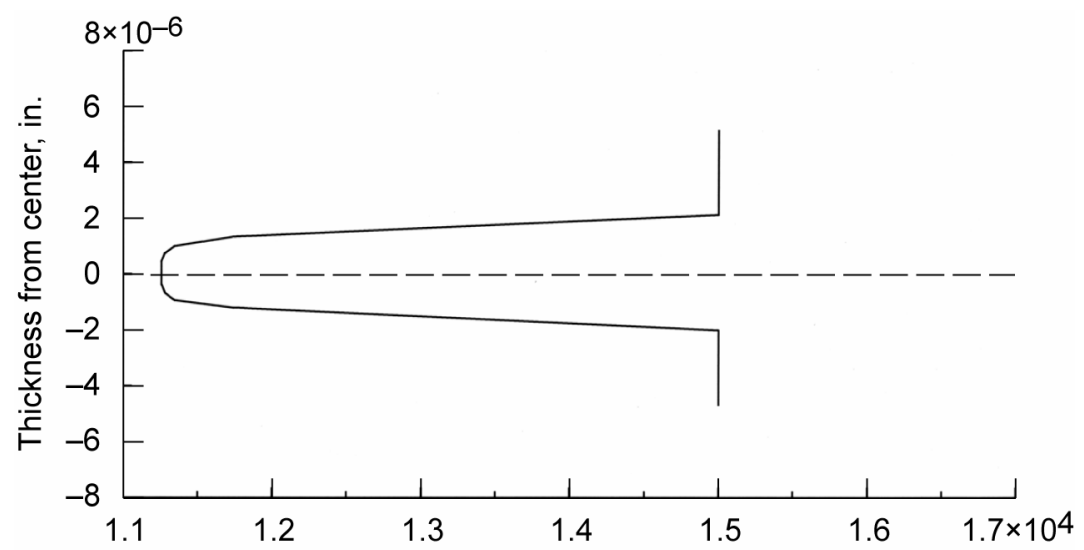

Figure 36.-Nanoscale uniaxial in-plane shear strength, $\mathrm{S}_{\ell 12 \mathrm{~S}}\left(\mathrm{lb} / \mathrm{in} .{ }^{2}\right)$.

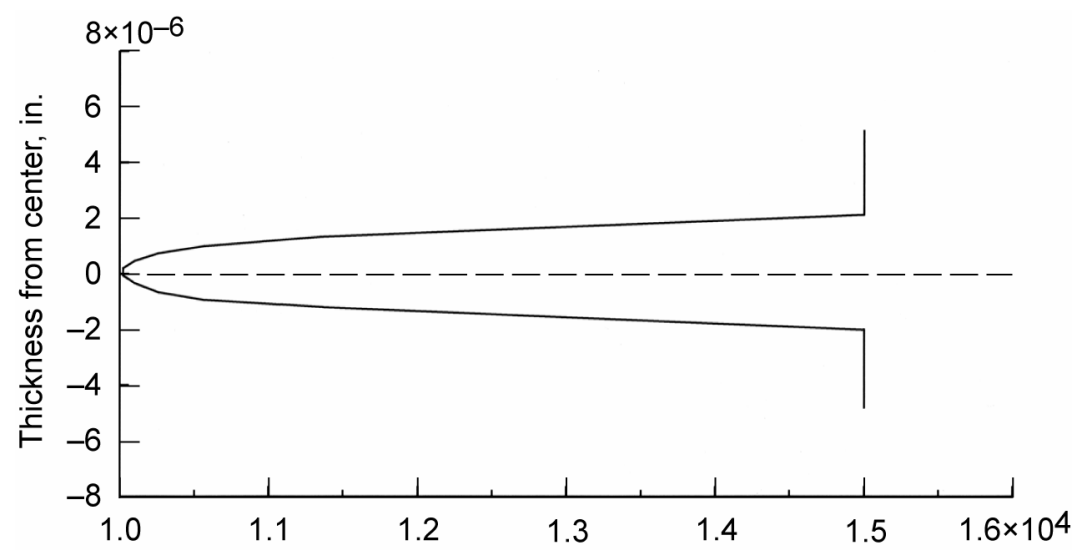

Figure 37.-Nanoscale uniaxial transverse tensile strength, $\mathrm{S}_{\ell 23 \mathrm{~T}}\left(\mathrm{Ib} / \mathrm{in} .^{2}\right.$ ).

This property is the last of the mechanical properties. All the fabrication parameters, the physical variables and the mechanical properties moduli and uniaxial strengths of the unidirectional (fiber aligned) nanolaminate have been completely characterized computationally.

\section{Concluding Remarks}

The salient remarks from an investigation to characterize an aligned monofiber nanolaminate are as follows:

1. The characterization for the nanolaminate (composite) was based on a series of progressive substructuring down a sliced single-diameter fiber where all the equations are based.

2. The theoretical development and all the equations are included in a computer code called ICAN/JAVA.

3. The characterization includes the following 25 properties: in situ fabrication parameters (3), physical variables (10), and mechanical properties (12) (6 moduli and 6 uniaxial strengths).

4. These properties are plotted graphically versus the nanolaminate thickness as ordinate.

5. The nanolaminate investigated consists of single nanofiber laminate with 0.05 weighted fiber volume ratio.

6. The nanofiber diameter is $2.756 \times 10^{-6}$ in. 
7. All the figures are symmetric about the midheight; most of them exhibit continuous behavior as would be expected. There is one exception: the through-the-thickness Poisson's ratio exhibits bimodal symmetric behavior.

8. The formulation and results are possible where the fiber diameter is a variable in the formulation and including the fiber, matrix, and void volume ratios input quantities into the computer code.

\section{References}

1. Jose, M., Tyner, J., Nyairo, E., and Dean, D. "Synthesis and Processing of Aligned Carbon Nanotube Based Fibers," presented at the 49th International SAMPE Symposium and Exhibition, (CD). May 16-20, 2004.

2. Ayalasomayajuala, G., Garg, A., Kapila, S., Chandrashekhara, K., and Flanigan, V. "Fabrication and Evaluation of Rice Hull Derived Nano Silica Composites," presented at the 49th International SAMPE Symposium and Exhibition (CD). May 16-20, 2004.

3. Karaki, T., Killgore, J.P., and Seferis, J.C. "Characterization of Fatigue Behavior of Polynanomeric Matrix Composites," presented at the 49th International SAMPE Symposium and Exhibition (CD). May 16-20, 2004.

4. Ranade, A., D'Souza, N.A., Nayak, K., Gnade, B., and Fairbrother, D. 2003. Correlation Between Creep-Recovery, Crystallization and Dispersion of Linear Low Density Polyethylene Nanocomposite Films, 48th International Symposium and Exhibition, vol. 48, book 1 of 2, pp. 2164-2176.

5. Koo, J.H., Stretz, H., Weispfenning, J., Luo, Z.P., and Wootan, W. "Nanocomposite Rocket Ablative Materials: Subscale Ablation Test," presented at the 49th International SAMPE Symposium and Exhibition, (CD). May 16-20, 2004.

6. Muhle, S., Monner, H.P., and Wiersch, P. 2003. Carbon-Nanotubes for Adaptive Structures, 48th International SAMPE Symposium and Exhibition, vol. 48, book 1 of 2, pp. 1181-1190.

7. Srivastava, D. and Wei, C. 2003. Computer Simulations of Macroscopic Properties of CarbonNanotube Polymer Composites, 48th International SAMPE Symposium and Exhibition, vol. 48, book 1 of 2, pp. 2153-2163.

8. Gates, T.S., et al. "Computational Materials: Multi-scale Modeling and Simulation of Nanostructural Materials." Composites Science and Technology, 65 (2005), pp. 2416-2434.

9. Naiwa, H.S. Editor, 2002. "Nanostructured Materials and Nanotechnology." Academic Press, San Diego, CA.

10. Handler, L.M. and Chamis, C.C. ICAN/JAVA Computer Code.

11. Chamis, C.C.: "Simplified Composite Micromechanics Equations for Hygral, Thermal and Mechanical Properties," NASA TM-83320, February 1983.

12. Chamis, C.C.: "Simplified Composite Equations for Strength, Fracture, Toughness, Impact Resistance and Environmental Effects," NASA TM-83696, January 1984.

13. Freund, M.M., Pomrenke, G.S., Brown, G.J. and Vaia, R.A. 2005. "Nanoscience and Technology for the Air Force," AFRL Technology Horizons, pp. 9-13. 


\begin{tabular}{|c|c|c|c|}
\hline \multicolumn{3}{|c|}{ REPORT DOCUMENTATION PAGE } & $\begin{array}{l}\text { Form Approved } \\
\text { OMB No. 0704-0188 }\end{array}$ \\
\hline \multicolumn{4}{|c|}{ 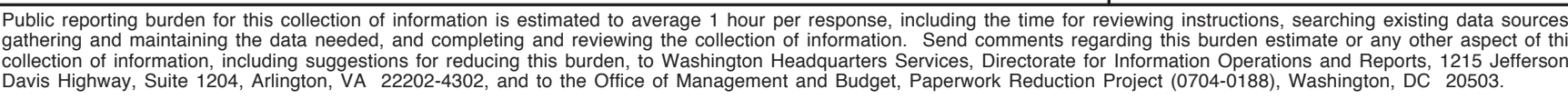 } \\
\hline 1. AGENCY USE ONLY (Leave blank) & $\begin{array}{l}\text { 2. REPORT DATE } \\
\text { February } 2007\end{array}$ & & $\begin{array}{l}\text { ID DATES COVERED } \\
\text { echnical Memorandum }\end{array}$ \\
\hline \multicolumn{4}{|c|}{ Composite Nanomechanics: A Mechanistic Properties Prediction } \\
\hline $\begin{array}{l}\text { 6. AUTHOR(S) } \\
\text { Christos C. Chamis, Louis N }\end{array}$ & andler, and Jane Mander & & WBS 984754.02.07.03 \\
\hline \multicolumn{3}{|c|}{$\begin{array}{l}\text { 7. PERFORMING ORGANIZATION NAME(S) AND ADDRESS(ES) } \\
\text { National Aeronautics and Space Administration } \\
\text { John H. Glenn Research Center at Lewis Field } \\
\text { Cleveland, Ohio } 44135-3191\end{array}$} & $\begin{array}{l}\text { 8. PERFORMING ORGANIZATION } \\
\text { REPORT NUMBER } \\
\text { E-15643 }\end{array}$ \\
\hline \multicolumn{2}{|c|}{$\begin{array}{l}\text { 9. SPONSORING/MONITORING AGENCY NAME(S) AND ADDRESS(E } \\
\text { National Aeronautics and Space Administration } \\
\text { Washington, DC 20546-0001 }\end{array}$} & & $\begin{array}{l}\text { 10. SPONSORING/MONITORING } \\
\text { AGENCY REPORT NUMBER } \\
\text { NASA TM-2007-214673 }\end{array}$ \\
\hline
\end{tabular}

\begin{tabular}{l|l|}
\hline 12a. DISTRIBUTION/AVAILABILITY STATEMENT & 12b. DISTRIBUTION CODE \\
Unclassified - Unlimited & \\
Subject Category: 24 & \\
Available electronically at http://gltrs.grc.nasa.gov \\
This publication is available from the NASA Center for AeroSpace Information, 301-621-0390.
\end{tabular}

13. ABSTRACT (Maximum 200 words)

A unique mechanistic theory is described to predict the properties of nanocomposites. The theory is based on composite micromechanics with progressive substructuring down to a nanoscale slice of a nanofiber where all the governing equations are formulated. These equations have been programmed in a computer code. That computer code is used to predict 25 properties of a mononanofiber laminate. The results are presented graphically and discussed with respect to their practical significance. Most of the results show smooth distributions. Results for matrix-dependent properties show bimodal through-the-thickness distribution with discontinuous changes from mode to mode.

\begin{tabular}{|c|c|c|c|}
\hline \multicolumn{3}{|c|}{$\begin{array}{l}\text { 14. SUBJECT TERMS } \\
\text { Nanofibers; Nanointerphase; Fabrication-variables; Physical-properties; Mechanic- } \\
\text { properties; Uniaxial-strengths; Monofiber ply; Nanoscale; Fabrication parameters; } \\
\text { Physical; Mechanical; Strengths; Nanoply properties }\end{array}$} & $\begin{array}{l}\text { 15. NUMBER OF PAGES } \\
28 \\
\text { 16. PRICE CODE }\end{array}$ \\
\hline Unclassified & Unclassified & Unclassified & \\
\hline NSN 7540-01-280-5500 & & & $\begin{array}{l}\text { ndard Form } 298 \text { (Rev. 2-89) } \\
\text { cribed by ANSI Std. Z39-18 } \\
102\end{array}$ \\
\hline
\end{tabular}



